\title{
Financial Intermediaries and Markets
}

\author{
Franklin Allen \\ Department of Finance \\ Wharton School \\ University of Pennsylvania \\ Philadelphia, PA 19104 \\ allenf@wharton.upenn.edu
}

\author{
Douglas Gale \\ Department of Economics \\ New York University \\ 269 Mercer Street \\ New York, NY 10003 \\ douglas.gale@nyu.edu
}

December 19, 2003 


\begin{abstract}
A complex financial system comprises both financial markets and financial intermediaries. We distinguish financial intermediaries according to whether they issue complete contingent contracts or incomplete contracts. Intermediaries such as banks that issue incomplete contracts, e.g., demand deposits, are subject to runs, but this does not imply a market failure. A sophisticated financial system - a system with complete markets for aggregate risk and limited market participation - is incentive-efficient, if the intermediaries issue complete contingent contracts, or else constrained-efficient, if they issue incomplete contracts. We argue that there may be a role for regulating liquidity provision in an economy in which markets for aggregate risks are incomplete.
\end{abstract}




\section{Markets, intermediaries and crises}

For a long time, it has been taken as axiomatic that financial crises are best avoided. We confront this conventional wisdom by showing that, under certain conditions, a laisser-faire financial system achieves the incentive-efficient or constrained-efficient allocation. ${ }^{1}$. Furthermore, constrained efficiency may require financial crises in equilibrium. The assumptions needed to achieve these efficiency results are restrictive, but no more so than the assumptions normally required to ensure Pareto-efficiency of Walrasian equilibrium. The important point is that optimality of avoiding crises should not be taken as axiomatic. If regulation is required to minimize or obviate the costs of financial crises, it should be justified by a microeconomic welfare analysis based on standard assumptions. Furthermore, the form of the intervention should be derived from microeconomic principles. Financial institutions and financial markets exist to facilitate the efficient allocation of risks and resources. Any government intervention will have an impact on the normal functioning of the financial system. A policy of preventing financial crises will inevitably create distortions. One of the advantages of a microeconomic analysis of financial crises is that it clarifies the costs and benefits of these distortions.

Policy analyses of banking and securities markets tend to be based on very specific models. ${ }^{2}$ In the absence of a general equilibrium framework, it is hard to evaluate the robustness of the results and, ultimately, to answer the question: What precisely are the market failures associated with financial crises? In this paper, we take a step toward developing a general model to analyze market failures in the financial sector and study a complex, decentralized, financial system comprising both financial markets and financial intermediaries. ${ }^{3}$ For the most part, the seminal models of bank runs, such as Bryant (1980) and Diamond and Dybvig (1983), analyze the behavior of a single bank and consist of a contracting problem followed by a coordination problem. ${ }^{4}$ We combine recent developments in the theory of bank-

\footnotetext{
${ }^{1}$ Wallace (1990) suggests that bank runs might be efficient. Examples of efficient bank runs were provided by Alonso (1996) and Allen and Gale (1998). Here we provide general sufficient conditions for the efficiency of financial crises.

${ }^{2}$ See Bhattacharya and Thakor (1993) for a survey. For examples of more recent work that stresses the analysis of welfare, see Matutes and Vives (1996, 2000).

${ }^{3}$ In this paper we use the term "financial markets" narrowly to denote markets for securities. Other authors have allowed for markets in which mechanisms are traded (e.g., Bisin and Gottardi (2000)). We prefer to call this intermediation. Formally, the two activities are similar, but in practice the economic institutions are quite different.

${ }^{4}$ Early models of financial crises were developed in the 1980s by Bryant (1980) and Diamond and Dybvig (1983). Important contributions were also made by Chari and Jagannathan (1988), Chari (1989), Champ, Smith, and Williamson (1996), Jacklin (1986), Jacklin and Bhattacharya (1988), Postlewaite and Vives (1986), Wallace $(1988 ; 1990)$ and others. Theoretical research on speculative currency attacks, banking panics, the role of liquidity and contagion have taken a number of approaches. One is built on the foundations provided by early research on bank runs (e.g., Hellwig (1994; 1998), Diamond (1997), Allen and Gale (1998; 1999; 2000a; 2000b), Peck and Shell (1999), Chang and Velasco (2000; 2001)) and Diamond and Rajan (2001)). Other approaches include those based on macroeconomic models of currency crises that developed from the insights of Krugman (1979), Obstfeld (1986) and Calvo (1988) (see, e.g., Corsetti, Pesenti, and Roubini (1999) for a recent contribution and Flood and Marion (1999) for a survey), game theoretic models
} 
ing with further innovations to model a complex financial system. The model has several interesting features: it introduces markets into a general-equilibrium theory of institutions; it endogenizes the cost of forced liquidation $;^{5}$ it allows for a fairly general specification of the economic environment; it allows for interaction between liquidity and asset pricing; ${ }^{6}$ and it allows us to analyze the regulation of the financial system using the standard tools of welfare economics.

In our model, intermediaries have two functions. Following Diamond and Dybvig (1983), intermediaries are providers of insurance services. By pooling the assets of individuals with uncertain preference for liquidity they can provide a higher degree of liquidity for any given level of returns on the portfolio. Their second function is to provide risk sharing services by packaging existing claims on behalf of investors who do not have access to markets. In this respect the intermediary operates more like a mutual fund, but both functions are essential to the operation of an optimal intermediary. Financial intermediaries have many other functions, of course, including payments, information gathering, lending, and underwriting, but we ignore these for the purpose of focusing on risk sharing and macroeconomic stability.

We distinguish between intermediaries that can offer complete contingent contracts and intermediaries that can only offer incomplete contracts. An example of the latter would be banks that can only offer deposit contracts. With complete contracts, the consequences of default can be anticipated and included in the contract, so without loss of generality we can assume default does not occur. With incomplete contracts, however, default can improve welfare by increasing the contingency of the contract (see, for example, Zame (1993)).

Aggregate risk in our model takes the form of shocks to asset returns and preferences. Formally, there is a finite set of aggregate states of nature that determines asset returns and preferences. We contrast economies with complete markets, in which there is a complete set of Arrow securities, one for each aggregate state, from economies with incomplete markets, in which the set of Arrow securities is less than the number of aggregate states. This produces a $2 \times 2$ classification of models, according to the completeness of contracts and markets.

\begin{tabular}{ll|l|}
\multicolumn{1}{c}{} & \multicolumn{1}{l}{ Complete markets } & \multicolumn{1}{l}{ Incomplete markets } \\
\cline { 2 - 3 } Complete contracts & incentive-efficient & not efficient \\
\cline { 2 - 3 } Incomplete contracts & constrained-efficient & not efficient \\
\cline { 2 - 3 } & &
\end{tabular}

Financial crises do occur in our model, but are not necessarily a source of market failure. A sophisticated financial system provides optimal liquidity and risk sharing, where a financial system is "sophisticated" if markets for aggregate risks are complete and market participation

(see Morris and Shin (1998), Morris (2000) and Morris and Shin (2000) for an overview), amplification mechanisms (e.g., Cole and Kehoe (2000) and Chari and Kehoe (2000)) and the borrowing of foreign currency by firms (e.g., Aghion, Bacchetta and Banerjee (2000)).

${ }^{5}$ Most of the literature, following Diamond and Dybvig (1983), assumes the existence of a technology for liquidating projects. Here we assume that a financially distressed institution sells assets to other institutions. This realistic feature of the model has important implications for welfare analysis. Ex post, liquidation does not entail a deadweight cost because assets are merely transferred from one owner to another. Ex ante, liquidation can result in inefficient risk sharing, but only if markets for hedging the risk are incomplete.

${ }^{6}$ In particular, there is a role for cash-in-the-market pricing (Allen and Gale (1994)). 
is incomplete. Efficiency depends on the completeness of markets but does not depend on whether contracts are complete or incomplete.

These results provide a benchmark for evaluating government intervention and regulation. If a sophisticated financial system leads to an incentive-efficient or constrained-efficient allocation, what precisely is the role of the government or central bank in intervening in the financial system? What can the government or central bank do that private institutions and the market cannot do? Our efficiency theorem assumes that markets for aggregate risk are complete. Missing markets may provide a role for government intervention.

In addition, the model provides some important insights into the working of complex financial systems. We include a series of examples to illustrate the properties of the model. In particular, we show that, in some cases, (a) existence and optimality require that equilibria be "mixed", that is, identical banks choose very different risk strategies; (b) default and crises are optimal when markets are complete and contracts incomplete; (c) asset pricing in a crisis is determined by the amount of liquidity in the market as well as by the asset returns; and (d) risk sharing is suboptimal with incomplete markets.

Our results are related to a small but important literature that seeks to extend the traditional intermediation literature in a more general equilibrium direction. Von Thadden (1999) also studies an integrated model of demand deposits and anonymous markets. Martin (2000) addresses the question of whether liquidity provision by the central bank can prevent crises without creating a moral hazard problem. Gromb and Vayanos (2001) study asset pricing in a model of collateralized arbitrage.

The rest of the paper is organized as follows. Section 2 describes the primitives of the model. Section 3 explores the welfare properties of liquidity provision and risk sharing in the context of an economy with a sophisticated financial system in which institutions take the form of general intermediaries. Section 4 shows that incomplete participation is critical for the optimality results achieved in the previous two sections. Section 5 extends this analysis to an economy with a sophisticated financial system in which institutions use incomplete contracts. In Section 6, we consider an economy with incomplete markets and characterize the conditions under which welfare can be increased by in some cases increasing and in some cases decreasing liquidity. Section 7 contains some final remarks and some of the proofs are gathered together in Section 8.

\section{The basic economy}

There are three dates $t=0,1,2$ and a single good at each date. The good is used for consumption and investment.

The economy is subject to two kinds of uncertainty. First, individual agents are subject to idiosyncratic preference shocks, which affect their demand for liquidity (these will be described later). Second, the entire economy is subject to aggregate shocks that affect asset returns and the cross-sectional distribution of preferences. The aggregate shocks are represented by a finite number of states of nature, indexed by $\eta \in H$. At date 0 , all agents have a common prior probability density $\nu(\eta)$ over the states of nature. All uncertainty is 
resolved at the beginning of date 1 , when the state $\eta$ is revealed and each agent discovers his individual preference shock.

Each agent has an endowment of one unit of the good at date 0 and no endowment at dates 1 and 2. So, in order to provide consumption at dates 1 and 2, they need to invest.

There are two assets distinguished by their returns and liquidity structure. One is a short-term asset (the short asset), and the other is a long-term asset (the long asset). The short asset is represented by a storage technology: one unit invested in the short asset at date $t=0,1$ yields a return of one unit at date $t+1$. The long asset yields a return after two periods. One unit of the good invested in the long asset at date 0 yields a random return of $R(\eta)>1$ units of the good at date 2 if state $\eta$ is realized.

Investors' preferences are distinguished ex ante and ex post. At date 0 there is a finite number $n$ of types of investors, indexed by $i=1, \ldots, n$. We call $i$ an investor's ex ante type. An investor's ex ante type is common knowledge and hence contractible. The measure of investors of type $i$ is denoted by $\mu_{i}>0$. The total measure of investors is normalized to one so that $\sum_{i} \mu_{i}=1$.

While investors of a given ex ante type are identical at date 0 , they receive a private, idiosyncratic, preference shock at the beginning of date 1 . The date 1 preference shock is denoted by $\theta_{i} \in \Theta_{i}$, where $\Theta_{i}$ is a finite set. We call $\theta_{i}$ the investor's ex post type. Because $\theta_{i}$ is private information, contracts cannot be explicitly contingent on $\theta_{i}$.

Investors only value consumption at dates 1 and 2. An investor's preferences are represented by a von Neumann-Morgenstern utility function, $u_{i}\left(c_{1}, c_{2} ; \theta_{i}\right)$, where $c_{t}$ denotes consumption at date $t=1,2$. The utility function $u_{i}\left(\cdot ; \theta_{i}\right)$ is assumed to be concave, increasing, and continuous for every type $\theta_{i}$. Diamond and Dybvig (1983) assumed that consumers were one of two ex post types, either early diers who valued consumption at date 1 or late diers who valued consumption at date 2 . This is a special case of the preference shock $\theta_{i}$. The present framework allows for much more general preference uncertainty.

The probability of being an investor of type $\left(i, \theta_{i}\right)$ conditional on state $\eta$ is denoted by $\lambda_{i}\left(\theta_{i}, \eta\right)>0$. The probability of being an agent of type $i$ is $\mu_{i}$. Consistency therefore requires that

$$
\sum_{\theta_{i}} \lambda_{i}\left(\theta_{i}, \eta\right)=\mu_{i}, \forall \eta \in H
$$

By the usual "law of large numbers" convention, the cross-sectional distribution of types is assumed to be the same as the probability distribution $\lambda$. We can therefore interpret $\lambda_{i}\left(\theta_{i}, \eta\right)$ as the number of agents of type $\left(i, \theta_{i}\right)$ in state $\eta$.

\section{Optimal intermediation}

Intermediaries have two broad functions in this model. First, because individual investors do not have access to markets for sharing aggregate risk, intermediaries trade existing claims on their behalf to produce a synthetic risk-sharing contract for the investors. In this respect, they are like mutual funds. Secondly, as in the Diamond-Dybvig model, intermediaries 
provide investors with insurance against the preference shocks. One difference from the Diamond-Dybvig model is that intermediaries cannot physically liquidate projects when they need liquidity. Instead, they sell assets on the capital market at date 1. Because their is no physical cost of liquidating assets, liquidation is ex post efficient: the buyer's loss is the seller's gain and vice versa.

In this section we assume that financial institutions take the form of general intermediaries. Each intermediary offers a single contract and each ex ante type is attracted to a different intermediary. Contracts are contingent on the aggregate states $\eta$ and individuals' reports of their ex post types, subject to incentive compatibility constraints.

One can, of course, imagine a world in which a single "universal" intermediary offers contracts to all ex ante types of investors. A universal intermediary could act as a central planner and implement the first-best allocation of risk. There would be no reason to resort to markets at all. Our world view is based on the assumption that transaction costs preclude this kind of centralized solution and that decentralized intermediaries are restricted in the number of different contracts they can offer. This assumption provides a role for financial markets in which financial intermediaries can share risk and obtain liquidity.

At the same time, financial markets alone will not suffice to achieve optimal risk sharing. Because individual economic agents have private information, markets for individual risks are incomplete. The markets that are available will not achieve an incentive-efficient allocation of risk. Intermediaries, by contrast, can offer individuals incentive-compatible contracts and improve on the risk sharing provided by the market.

In the Diamond-Dybvig (1983) model, all investors are ex ante identical. Consequently, a single representative bank can provide complete risk sharing and there is no need for markets to provide cross-sectional risk sharing across banks. Allen and Gale (1994) showed that differences in risk and liquidity preferences can be crucial in explaining asset prices. This is another reason for allowing for ex ante heterogeneity.

\subsection{Markets}

At date 0 investors deposit their endowments with an intermediary in exchange for a general risk sharing contract. The intermediaries have access to a complete set of Arrow securities markets at date 0 . For each aggregate state $\eta$ there is a security traded at date 0 that promises one unit of the good at date 1 if state $\eta$ is observed and nothing otherwise. Let $q(\eta)$ denote the price of one unit of the Arrow security corresponding to state $\eta$, that is, the number of units of the good at date 0 needed to buy one unit of the good in state $\eta$ at date 1 .

All uncertainty is resolved at the beginning of date 1. Consequently there is no need to trade contingent securities at date 1 . Instead, we assume there is a spot market and a forward market for the good at date 1 . The good at date 1 is the numeraire so $p_{1}(\eta)=1$; the price of the good at date 2 for sale at date 1 is denoted by $p_{2}(\eta)$, i.e., $p_{2}(\eta)$ is the number of units of the good at date 1 needed to purchase one unit of the good at date 2 in state $\eta$. Let $p(\eta)=\left(p_{1}(\eta), p_{2}(\eta)\right)=\left(1, p_{2}(\eta)\right)$ denote the vector of goods prices at date 1 in state $\eta$. 
Note that we do not assume the existence of a technology for physically liquidating projects. Instead, we follow Allen and Gale (1998) in assuming that an institution in distress sells long-term assets to other institutions. From the point of view of the economy as a whole, the long-term assets cannot be liquidated - someone has to hold them.

\subsection{Intermediation mechanisms}

Investors participate in markets indirectly, through intermediaries. An intermediary is a risk-sharing institution that invests in the short and long assets on behalf of investors and provides them with consumption at dates 1 and 2. Intermediaries use markets to hedge the risks that they manage for investors.

Each investor of type $i$ gives his endowment (one unit of the good) to an intermediary of type $i$ at date 0 . In exchange, he gets a bundle of goods $x_{i}\left(\theta_{i}, \eta\right) \in \mathbf{R}_{+}^{2}$ at dates 1 and 2 in state $\eta$ if he reports the ex post type $\theta_{i}$. In effect, the function $x_{i}=\left\{x_{i}\left(\theta_{i}, \eta\right)\right\}$ is a direct mechanism that maps agents' reports into feasible consumption allocations. ${ }^{7}$

A feasible mechanism is incentive-compatible. The appropriate definition of the incentivecompatibility constraint must take into account the fact that agents can use the short asset to store the good from date 1 to date 2. Suppose that the agent receives a consumption bundle $x_{i}\left(\theta_{i}, \eta\right)$ from the intermediary. By saving, he can obtain any consumption bundle $c \in \mathbf{R}_{+}^{2}$ such that

$$
c_{1} \leq x_{i 1}\left(\theta_{i}, \eta\right), \sum_{t=1}^{2} c_{t} \leq \sum_{t=1}^{2} x_{i t}\left(\theta_{i}, \eta\right) .
$$

Let $C\left(x_{i}\left(\theta_{i}, \eta\right)\right)$ denote the set of consumption bundles satisfying (1). The maximum utility that can be obtained from the consumption bundle $x_{i}\left(\theta_{i}, \eta\right)$ by saving is denoted by $u_{i}^{*}\left(x_{i}\left(\theta_{i}, \eta\right), \theta_{i}\right)$ and defined by

$$
u_{i}^{*}\left(x_{i}\left(\theta_{i}, \eta\right), \theta_{i}\right)=\sup \left\{u_{i}\left(c, \theta_{i}\right): c \in C\left(x_{i}\left(\theta_{i}, \eta\right)\right)\right\} .
$$

Then the incentive constraint with saving can be written as:

$$
u_{i}\left(x_{i}\left(\theta_{i}, \eta\right), \theta_{i}\right) \geq u_{i}^{*}\left(x_{i}\left(\hat{\theta}_{i}, \eta\right), \theta_{i}\right), \forall \theta_{i}, \hat{\theta}_{i} \in \Theta_{i}, \forall \eta \in H .
$$

Notice that by placing $u_{i}(\cdot)$ on the left hand side of $(2)$, we ensure that even a truth-telling agent will not want to save outside of the intermediary. There is no loss of generality in this restriction, since the intermediary can tailor the timing of consumption to the agent's needs. Let $X_{i}$ denote the set of incentive-compatible mechanisms when the depositor has access to the storage technology.

\footnotetext{
${ }^{7} \mathrm{~A}$ direct mechanism is normally a function that assigns a unique outcome to each profile of types chosen by the investors. In a symmetric direct mechanism, the outcome for a single investor depends only on the individual's report and the distribution of reports by other investors. In a truth-telling equilibrium, the reports of other investors are given by the distribution $\lambda(\cdot, \eta)$ so a symmetric direct mechanism should properly be written $x_{i}\left(\theta_{i}, \lambda(\cdot, \eta), \eta\right)$ but since $\lambda(\cdot, \eta)$ is given as a function of $\eta$ there is no loss of generality in suppressing the reference to $\lambda(\cdot, \eta)$.
} 


\subsection{Equilibrium}

Recall that each intermediary issues a single contract and serves a single ex ante type of investor. We denote by $i$ the representative intermediary that trades with the ex ante investor type $i$. The representative intermediary $i$ takes in deposits of $\mu_{i}$ units of the good at date 0 and invests in $y_{i} \geq 0$ units of the short asset and $\mu_{i}-y_{i} \geq 0$ units of the long asset. In exchange it offers depositors an incentive-compatible mechanism $x_{i}$. Given the prevailing prices $(p, q)$, a mechanism $x_{i}$ and investment portfolio $y_{i}$ yield non-negative profits for the intermediary if it satisfies the following "budget constraint":

$$
\sum_{\eta} q(\eta) \sum_{\theta_{i}} \lambda_{i}\left(\theta_{i}, \eta\right) p(\eta) \cdot x_{i}\left(\theta_{i}, \eta\right) \leq \sum_{\eta} q(\eta) p(\eta) \cdot\left(y_{i},\left(\mu_{i}-y_{i}\right) R(\eta)\right) .
$$

(In equilibrium, free entry will drive the value of profits to zero). In state $\eta$, the cost of goods given to investors who report $\theta_{i}$ is $p(\eta) \cdot x_{i}\left(\theta_{i}, \eta\right)$ and there are $\lambda\left(\theta_{i}, \eta\right)$ such agents, so summing across ex post types $\theta_{i}$ we get the total cost of the mechanism in state $\eta$ as $\sum_{\theta_{i}} \lambda\left(\theta_{i}, \eta\right) p(\eta) \cdot x_{i}\left(\theta_{i}, \eta\right)$. Multiplying by the cost of one unit of the good at date 1 in state $\eta$ and summing over states $\eta$ gives the total cost of the mechanism, in terms of units of the good at date 0 , as the left hand side of equation (3). The right hand side is the total value of investments by the intermediary. In state $\eta$ the short asset yields $y_{i}$ units of the good at date 1 and the long asset yields $\left(\mu_{i}-y_{i}\right) R(\eta)$ units of the good at date 2 so the total value of the portfolio is $p(\eta) \cdot\left(y_{i},\left(\mu_{i}-y_{i}\right) R(\eta)\right)$. Multiplying by the price of a unit of the good at date 1 in state $\eta$ and summing across states gives the total value of the investments by the intermediary, in terms of units of the good at date 0 .

An intermediated allocation specifies an incentive-compatible mechanism $x_{i}$ and a feasible portfolio $y_{i}$ for each representative intermediary $i=1, \ldots, n$. An intermediated allocation $\left\{\left(x_{i}, y_{i}\right)\right\}$ is attainable if it satisfies the market-clearing conditions at dates 1 and 2 , that is, for each intermediary $i$,

$$
\sum_{i} \sum_{\theta_{i}} \lambda_{i}\left(\theta_{i}, \eta\right) x_{i 1}\left(\theta_{i}, \eta\right) \leq \sum_{i} y_{i}, \forall \eta
$$

and

$$
\sum_{i} \sum_{\theta_{i}} \lambda_{i}\left(\theta_{i}, \eta\right)\left(x_{i 1}\left(\theta_{i}, \eta\right)+x_{i 2}\left(\theta_{i}, \eta\right)\right)=\sum_{i} y_{i}+\left(\mu_{i}-y_{i}\right) R(\eta), \forall \eta .
$$

Condition (4) says that the total consumption at date 1 in each state $\eta$ must be less than or equal to the supply of the good (equals the amount of the short asset). Condition (4) is an inequality because it is possible to transform an excess of the short asset at date 1 into consumption at date 2. Condition (5) says that the sum of consumption over the two periods is equal to the total returns from the two assets. Alternatively, we can read this as saying that consumption at date 2 is equal to the return on the long asset plus whatever is left over from date 1. 
An intermediary offers a contract $x_{i} \in X_{i}$ that maximizes the profit per contract, subject to a participation constraint

$$
\sum_{\eta} \sum_{\theta_{i}} \lambda\left(\theta_{i}, \eta\right) u_{i}\left(x_{i}\left(\theta_{i}, \eta\right), \theta_{i}\right) \geq \bar{u}_{i}
$$

where $\bar{u}_{i}$ is the maximum expected utility the $i$-th type can obtain from any other contract in the market. Hence, a pure intermediated equilibrium consists of a price system $\left(p^{*}, q^{*}\right)$ and an attainable allocation $\left\{\left(x_{i}^{*}, y_{i}^{*}\right)\right\}$ such that, for every intermediary $i$, the choice of mechanism $x_{i}^{*}$ and portfolio $y_{i}^{*}$ solves the decision problem

$$
\begin{array}{ll}
\max & \sum_{\eta} q^{*}(\eta) \sum_{\theta_{i}} \lambda_{i}\left(\theta_{i}, \eta\right) p^{*}(\eta) \cdot x_{i}\left(\theta_{i}, \eta\right)-\sum_{\eta} q^{*}(\eta) p^{*}(\eta) \cdot\left(y_{i},\left(\mu_{i}-y_{i}\right) R(\eta)\right) \\
\text { s.t. } & x_{i} \in X_{i} ; \\
& \sum_{\eta} \sum_{\theta_{i}} \lambda\left(\theta_{i}, \eta\right) u_{i}\left(x_{i}\left(\theta_{i}, \eta\right), \theta_{i}\right) \geq \sum_{\eta} \sum_{\theta_{i}} \lambda\left(\theta_{i}, \eta\right) u_{i}\left(x_{i}^{*}\left(\theta_{i}, \eta\right), \theta_{i}\right)
\end{array}
$$

and equilibrium profits are zero:

$$
\sum_{\eta} q^{*}(\eta) \sum_{\theta_{i}} \lambda_{i}\left(\theta_{i}, \eta\right) p^{*}(\eta) \cdot x_{i}\left(\theta_{i}, \eta\right)=\sum_{\eta} q^{*}(\eta) p^{*}(\eta) \cdot\left(y_{i},\left(\mu_{i}-y_{i}\right) R(\eta)\right) .
$$

Competition and free entry force the intermediaries to undercut one another by offering more attractive contracts to the investors. In equilibrium, the contract chosen maximizes the welfare of the typical depositor subject to a zero-profit constraint. (On the one hand, no intermediary will offer a contract that earns negative profits and, on the other, if the contract earns positive profits or fails to maximize the investor's expected utility, an entrant can steal customers and still make positive profits). Hence, the intermediary's decision problem is equivalent to the following:

$$
\begin{array}{ll}
\max & \sum_{\eta} \sum_{\theta_{i}} \lambda\left(\theta_{i}, \eta\right) u_{i}\left(x_{i}\left(\theta_{i}, \eta\right), \theta_{i}\right) \\
\text { s.t. } & x_{i} \in X_{i} ; \\
& \sum_{\eta} q(\eta) \sum_{\theta_{i}} \lambda_{i}\left(\theta_{i}, \eta\right) p(\eta) \cdot x_{i}\left(\theta_{i}, \eta\right) \leq \sum_{\eta} q(\eta) p(\eta) \cdot\left(y_{i},\left(\mu_{i}-y_{i}\right) R(\eta)\right) .
\end{array}
$$

In a pure equilibrium, we assume that all intermediaries serving type $i$ choose the same portfolio and contract. To ensure the existence of equilibrium, we need to allow for the possibility that intermediaries of type $i$ make different choices. A mixed allocation is defined by a finite set of numbers $\left\{\rho^{j}\right\}$ and allocations $\left\{\left(x_{i}^{j}, y_{i}^{j}\right)\right\}$ such that $\rho^{j} \geq 0$ and $\sum_{j} \rho^{j}=1$. A mixed allocation represents the following situation. The population is divided into groups. Each group $j$ is a representative sample of size $\rho^{j}$, that is, the relative frequency of ex ante types in group $j$ is the same as in the population at large. Each ex ante type $i$ in group $j$ is served by an intermediary which offers a contract $x_{i}^{j}$ and chooses a portfolio $y_{i}^{j}$. In a sense, we can think of $\left(x_{i}^{j}, y_{i}^{j}\right)$ as a pure allocation for group $j$, except that there is no requirement for group $j$ to be self-sufficient (there can be trade among groups) and each type $i$ must be indifferent among the different groups in equilibrium.

A mixed allocation is attainable if the mean $\left\{\left(x_{i}, y_{i}\right)\right\}=\sum_{j} \rho^{j}\left\{\left(x_{i}^{j}, y_{i}^{j}\right)\right\}$ satisfies the market-clearing conditions (4) and (5). Note that $\left\{\left(x_{i}, y_{i}\right)\right\}$ may not be an allocation: even if each $\left(x_{i}^{j}, y_{i}^{j}\right)$ belongs to $X_{i}$ the mean $\left(x_{i}, y_{i}\right)$ may not because the set $X_{i}$ is not convex. 
A mixed intermediated equilibrium consists of a price system $(p, q)$ and a mixed attainable allocation $\left\{\left(\rho^{j}, x_{i}^{j}, y_{i}^{j}\right)\right\}$ such that for every intermediary $i$, and every subgroup $j$, the choice $\left(x_{i}^{j}, y_{i}^{j}\right)$ solves the decision problem (6).

Assumption 1: (Non-empty interior) For any ex ante type $i=1, \ldots, n$, for any consumption bundle $x_{i} \in X_{i}$ and price system $p \in P$, and for any $\varepsilon>0$, either

$$
\sum_{\eta} p(\eta) \cdot\left(\sum_{\theta_{i}} \lambda\left(\theta_{i}, \eta\right) x_{i}\left(\theta_{i}, \eta\right)\right)=0
$$

or there exists a bundle $x_{i}^{\prime}$ within a distance $\varepsilon$ of $x_{i}$ such that

$$
\sum_{\eta} p(\eta) \cdot\left(\sum_{\theta_{i}} \lambda\left(\theta_{i}, \eta\right) x_{i}^{\prime}\left(\theta_{i}, \eta\right)\right)<\sum_{\eta} p(\eta) \cdot\left(\sum_{\theta_{i}} \lambda\left(\theta_{i}, \eta\right) x_{i}\left(\theta_{i}, \eta\right)\right) .
$$

Theorem 1 Under the maintained assumptions, there exists a mixed intermediated equilibrium, if Assumption 1 is satisfied.

Proof. See "Existence of Equilibrium: An Addendum to "Financial Institutions and Markets"" at http://www.nyu.edu/econ/user/galed/papers.html.

A pure equilibrium is a special case of a mixed equilibrium, but there is no guarantee that pure equilibria exist. In fact, we show in Section 5.1 that pure equilibria fail to exist in straightforward cases.

For some purposes it is useful to interpret a mixed intermediated equilibrium as a pure intermediated equilibrium with a different set of ex ante types. Let $(i, j)$ denote the new ex ante sub-type consisting of investors in the subgroup $j$ of ex ante type $i$ and let $\mu_{i j}=\rho^{j} \mu_{i}$ denote the measure of investors in the new ex ante type $(i, j)$. Notice that we have to define a distinct economy for every mixed intermediated equilibrium. This is because the weights $\mu_{i j}$ depend on the endogenous variables $\rho^{j}$. In a mixed equilibrium, all agents of given ex ante type $i$ receive the same expected utility. Thus, the expected utility of sub-type $(i, j)$ is the same as the expected utility of type $\left(i, j^{\prime}\right)$ for any given type $i$. Taking the weights $\left\{\mu_{i j}\right\}$ as given, we might be able to find other pure equilibria of the artificial economy, but they would not necessarily be mixed equilibria of the original economy, because they would not necessarily satisfy this equilibrium condition. For most purposes, this is not an issue, so without loss of generality we can restrict attention to pure equilibria.

\subsection{Efficiency}

Under mild assumptions, we can show that the equilibrium allocation is incentive-efficient. An attainable allocation $(x, y)=\left\{\left(x_{i}, y_{i}\right)\right\}$ is incentive efficient if there does not exist an attainable mixed allocation $\left\{\left(\rho^{j}, x_{i}^{j}, y_{i}^{j}\right)\right\}$ such that

$$
\sum_{\eta} \sum_{\theta_{i}} \lambda\left(\theta_{i}, \eta\right) u_{i}\left(x_{i}^{j}\left(\theta_{i}, \eta\right), \theta_{i}\right) \geq \sum_{\eta} \sum_{\theta_{i}} \lambda\left(\theta_{i}, \eta\right) u_{i}\left(x_{i}\left(\theta_{i}, \eta\right), \theta_{i}\right)
$$


for every $(i, j)$ with strict inequality for some $(i, j)$. (This definition differs from Pareto efficiency only to the extent that we restrict attention to the incentive-compatible mechanisms $\left.x_{i} \in X_{i}\right)$.

In order to prove the incentive-efficiency of equilibrium, we need an additional regularity condition:

Assumption 2: (Local non-satiation) For any ex ante type $i=1, \ldots, n$, for any mechanism $x_{i} \in X_{i}$, and for any $\varepsilon>0$, there exists a mechanism $x_{i}^{\prime} \in X_{i}$ within a distance $\varepsilon$ of $x_{i}$ such that

$$
\sum_{\eta} \sum_{\theta_{i}} \lambda\left(\theta_{i}, \eta\right) u_{i}\left(x_{i}^{\prime}\left(\theta_{i}, \eta\right), \theta_{i}\right)>\sum_{\eta} \sum_{\theta_{i}} \lambda\left(\theta_{i}, \eta\right) u_{i}\left(x_{i}\left(\theta_{i}, \eta\right), \theta_{i}\right)
$$

Remark: This assumption is the counterpart of the non-satiability assumptions used in the classical theorems of welfare economics. It requires more than the non-satiability of each ex post type's utility function, $u_{i}\left(\cdot, \theta_{i}\right)$, however because the incentive constraints must be satisfied also. To illustrate the meaning of Assumption 2, consider the following example. There are two ex post types $\theta_{i}=1,2$ with utility functions $u_{i}(c, 1)$ and $u_{i}(c, 2)$. The utility functions are defined as follows:

$$
\begin{gathered}
u_{i}(c, 1)=c_{1}+c_{2}, \\
u_{i}(c, 2)=c_{1}+c_{2} \text { if } c_{1}+c_{2} \leq 1
\end{gathered}
$$

and for any utility level $\bar{u}>1$, we denote the indifference curve consisting of the locus of consumption bundles yielding $\bar{u}$ to an agent of type $\theta_{i}=2$ by $I_{i}(\bar{u}, 2)$ and define it by putting

$$
I_{i}(\bar{u}, 2)=\left\{\left(c_{1}, c_{2}\right)=\left((1-\alpha) \frac{\bar{u}+1}{2}, \alpha \bar{u}\right): 0 \leq \alpha \leq 1\right\} .
$$

Notice that both types have linear indifference curves, but their indifference curves have different slopes at consumption bundles $c=\left(c_{1}, c_{2}\right)$ such that $c_{1}+c_{2}>1$. Now consider an incentive-compatible mechanism $x_{i}$ satisfying $x_{i}(1, \eta)=(1,0)$ and $x_{i}(2, \eta)=(0,1)$. Both incentive constraints (2) are just satisfied. Any mechanism $x_{i}^{\prime}$ that is $\varepsilon$-close to $x_{i}$ and makes type $i$ better off ex ante must make at least one of the ex post types better off and the incentive constraint then requires that the other ex post type be better off too. In other words, both of the consumption bundles $x_{i}^{\prime}(1, \eta)$ and $x_{i}^{\prime}(2, \eta)$ must lie above the line $c_{1}+c_{2}=1$. Above the line $c_{1}+c_{2}=1$, the two ex post types have linear indifference curves and the indifference curve of type 2 is steeper than that of ex post type 1 . Since $x_{i}^{\prime}\left(\theta_{i}, \eta\right)$ is very close to $x_{i}\left(\theta_{i}, \eta\right)$ for $\theta_{i}=1,2$ at least one type $\theta_{i}$ must envy the other. Thus, local non-satiation is not satisfied.

This example turns on the difference between lower hemi-continuity and not upper hemicontinuity. A convergent sequence of incentive-compatible allocations will have an incentivecompatible limit, but it may not be possible to approximate a given incentive-compatible allocation by a sequence of incentive-compatible allocations from certain directions. The line $c_{1}+c_{2}=1$ contains many incentive-compatible allocations but most of these cannot be approximated from above by a sequence of incentive-compatible allocations. 
Theorem 2 Under the maintained assumptions, if $(p, q, x, y)$ is an intermediated equilibrium and Assumption 2 is satisfied, then the allocation $(x, y)$ is incentive-efficient.

Proof. See Section 8.

Theorem 2 is in the spirit of Prescott and Townsend (1984a, b), but the present model takes the decentralization of the incentive-efficient allocation a step further. Markets are used in Prescott and Townsend (1984a, b) to allocate mechanisms to agents at the first date. After the first date all trade is intermediated by the mechanism. Here, markets are also used for sharing risk and for intertemporal smoothing and intermediaries are active participants in markets at each date. In Section 4 we show that efficiency requires that individuals do not have access to financial markets. To this extent, we follow PrescottTownsend in assuming that individuals' trade is intermediated by the mechanism. In Section 5 , we consider incomplete contracts and the possibility of default. In the event of default, individuals' trade is no longer intermediated by the mechanism.

Remark: An important qualification to the incentive-efficiency of the intermediated equilibrium is the "equilibrium selection" implicit in the definition of equilibrium. Following the standard principal-agent approach (see, e.g., Grossman and Hart (1983)), we allow the principal (the intermediary), to choose the actions of the agents (the investors), subject to an incentive-compatibility constraint. This assumption means that the intermediary can plan what to do in each state. The complete markets can be used to ensure that liabilities can be met in every state. As a result bankruptcy and financial crises cannot occur.

Remark: The incentive-efficiency of equilibrium is in marked contrast to the results in Bhattacharya and Gale (1987). The difference is explained by the informational assumptions. In the model above, there is no asymmetry of information in the markets for Arrow securities. Once the state $\eta$ is observed, all aggregate uncertainty is resolved. The distribution of ex post types in each intermediary is a function of $\eta$ and hence becomes common knowledge once $\eta$ is revealed. Trading Arrow securities at date 0 is sufficient to provide optimal insurance against all aggregate shocks at date 1. In Bhattacharya and Gale (1987), by contrast, an intermediary's true demand for liquidity is private information at date 1. Markets for Arrow securities cannot provide incentive-efficient insurance against private shocks.

While symmetry of information in financial markets is a useful benchmark, one can easily imagine circumstances in which intermediaries have private information, for example, the intermediary knows the distribution of ex post types among its depositors, but outsiders do not. In that case, providing incentive-efficient insurance to the intermediaries would require us to supplement markets for Arrow securities with an incentive-compatible insurance mechanism, as in Bhattacharya and Gale (1987).

\subsection{Examples}

In this subsection we consider a series of numerical examples with complete markets and complete contracts with respect to aggregate states. These provide an efficient benchmark for subsequent examples with incomplete markets and/or contracts. We look first at an example of asset-return shocks and then look at an example with liquidity shocks. 


\section{Return shocks}

Example 1: We assume there is a single ex ante type of investor with Diamond-Dybvig preferences. There are two ex post types, early consumers $(\theta=1)$ and late consumers $(\theta=2)$. The utility function is

$$
u\left(c_{1}, c_{2}, \theta\right)= \begin{cases}\log c_{1} & \theta=1 \\ \log c_{2} & \theta=2\end{cases}
$$

The probability of being an early consumer is one half, independently of the aggregate state $\eta$. There are two equally likely aggregate states $\eta=1,2$ and the return on the long asset at date 2 is contingent on the state:

$$
R(1)=r ; R(2)=2 \text {. }
$$

Different equilibria are generated by varying $r$.

Since investors are ex ante identical, the open interest in Arrow securities will be 0 in equilibrium.

Since the investors are either early or late consumers, the optimal bundles will be of the form $x(\theta, \eta)=\left\{\left(c_{1}(\eta), 0\right),\left(0, c_{2}(\eta)\right)\right\}$ with early consumers consuming $c_{1}(\eta)$ at date 1 and late consumers consuming $c_{2}(\eta)$ at date 2 . The market-clearing conditions are:

$$
\begin{gathered}
0.5 c_{1}(\eta) \leq y \\
0.5 c_{1}(\eta)+0.5 c_{2}(\eta)=y+(1-y) R(\eta)
\end{gathered}
$$

for $\eta=1,2$.

The form of the equilibrium depends on whether (7) is binding. In the first type of equilibrium, it binds in both states; in the second, it only binds in state 2 ; in the third, it does not bind in either state.

Example 1A. For $R(1)=r>1$, equilibrium is unique and $0.5 c_{1}(\eta)=y$ in both states. A typical equilibrium with $r=1.5$ is shown in Table 1 . The intermediary puts 0.5 in the safe asset and 0.5 in the risky asset. The early consumers receive 1 at date 1 irrespective of the state, and late consumers receive 1.5 in state 1 and 2 in state 2 . With these allocations it is clear that the incentive constraint does not bind. No late consumer would choose 1 at date 1 rather than 1.5 or 2 at date 2. The Arrow securities are priced at 0.5 for both states. The date 1 spot price of consumption is higher in state 1 than state 2 because date 2 consumption is lower and marginal utility is higher in state 1.

Example 1B. For $0.4 \leq r<1$, the unique pure intermediated equilibrium is such that the consumption profile satisfies $0.5 c_{1}(1)<y$ and $0.5 c_{1}(2)=y$. In state 1 , the returns to the long asset are so low that some of the short asset must be saved to provide consumption at date 2 ; in state 2 , all of the short asset is consumed at date 1 . In order for the intermediaries to be willing to hold the short asset between date 1 and date 2 in state 1 , the price must 
be equal to 1 . Thus, consumption is equalized across time in state 1 . The amount invested in the short asset rises as the expected payoff on the long asset falls. Table 1 illustrates the equilibrium values for the case where $r=0.5$. The amount invested in the safe asset has moved up to 0.64 , in state $1 p_{2}(1)=1$ and consumption is the same at both dates.

Example 1C. It remains to consider the case $0 \leq r \leq 0.4$. As $r$ continues to fall the intermediary invests more in the short asset and less in the long asset. The total output and consumption in state 2 are also falling and for $r<0.4$ the consumption at date 1 is less than the holding of the short asset in both states: $0.5 c_{1}(\eta)<y$. Consumption is equalized across time in both states. The equilibrium values corresponding to $r=0.3$ are given in Table 1 . Here $y=0.78, p_{1}(1)=p_{2}(1)=1$ and in both states consumptions are equated at each date.

The next example introduces a second ex ante type consisting of risk neutral investors. The purpose of this example is to illustrate how the Arrow securities allow cross-sectional risk sharing and to show their role in ensuring an incentive-efficient allocation.

Example 2. There are two ex ante types of investors, the risk averse investors, denoted by $A$, and the risk neutral investors denoted by $N$. The period utility functions are $U_{A}(c)=\log (c)$ and $U_{N}(c)=c$, respectively. The measure of each type is normalized to 1 and each type has a probability 0.5 of being an early or late consumer. Otherwise things are the same as in Example 1.

As in Example 1, the qualitative features of the equilibrium depend on whether some of the short asset is carried over from date 1 to date 2 . One case is sufficient to illustrate how the Arrow securities allow risk to be shared. For $r \geq 0.4$ the allocation is the same as in Example 1A, except that all uncertainty is absorbed by the risk neutral type. The equilibrium portfolios are $y_{A}=0.5$ and $y_{N}=0$, for the representative intermediaries of type $A$ and type $N$, respectively.

Table 1 gives the equilibrium values for the case where $r=0.5$. The market-clearing prices are $q(1)=0.5, q(2)=0.5, p_{2}(1)=0.8, p_{2}(2)=0.8$. The portfolio returns (receipts) of each intermediary and consumption of each type are given in the following table.

\begin{tabular}{||l|l|l||}
\hline \hline & State 1 & State 2 \\
\hline$\left(y_{A}, R(\eta)\left(1-y_{A}\right)\right)$ & $(0.5,0.25)$ & $(0.5,1)$ \\
$\left(y_{N}, R(\eta)\left(1-y_{N}\right)\right)$ & $(0,0.5)$ & $(0,2)$ \\
$\left(c_{A 1}(\eta), c_{A 2}(\eta)\right)$ & $(1,1.25)$ & $(1,1.25)$ \\
$\left(c_{N 1}(\eta), c_{N 2}(\eta)\right)$ & $(0,0.25)$ & $(0,4.75)$ \\
\hline \hline
\end{tabular}

Risk sharing between the intermediaries for the two groups is achieved through trading in the Arrow-security markets at date 0 and the spot consumption markets at date 1 . In state 1 the type $A$ intermediaries have 0.5 of the good from their short asset holdings. They have promised each of their 0.5 early consumers 1 unit of the good each so they can simply pay out what they receive from the short asset to meet their obligations. At date 2 they receive 0.25 from their holdings of the long asset. They have promised their 0.5 late consumers 
1.25 each. The deficit is $0.5 \times 1.25-0.25=0.375$. To ensure that they have this they need to use the $\eta=1$ Arrow security and the spot market at date 1 . They purchase 0.3 units of the $\eta=1$ Arrow security at date 0 for $q(1) \times 0.3=0.5 \times 0.3=0.15$ and then use the 0.3 they receive at date 1 in state 1 to purchase $0.3 / p_{2}(1)=0.3 / 0.8=0.375$ of the date 2 good in the date 1 spot market. At date 0 they finance the 0.15 needed to purchase the $\eta=1$ Arrow security by selling 0.375 of the good at date 2 in state 2 and 0.3 of the $\eta=2$ Arrow security. Since they have 1 unit of output from their long asset at date 2 this will leave them with 0.625 of the good to pay out to their 0.5 late consumers who receive 1.25 each. The type $N$ 's are willing to take the other side of these trades since they are risk neutral. It can be seen that this improvement in risk sharing increases the expected utility of type $A$ 's from 0.054 in Example 1B to 0.112 here.

There are other intermediated equilibria corresponding to these parameter values. In particular, the portfolio holdings of the type- $A$ intermediaries are not uniquely determined. For example, the type- $A$ intermediaries could hold less of the short term asset and more of the long term asset, as long as this is offset by changes in the holdings of the type- $N$ intermediaries. As long as the aggregate portfolio remains the same, investors' consumption and welfare is unchanged.

\section{Liquidity shocks}

The uncertainty in Examples 1 and 2 is generated by shocks to asset returns. Similar results can be obtained by assuming aggregate uncertainty about the demand for liquidity.

Example 3. This example is similar to Example 1. There are two main differences. First, it is assumed that there is no uncertainty about the return to the long asset:

$$
R(1)=R(2)=r \text {. }
$$

Second, there is aggregate uncertainty about the demand for liquidity. The states $\eta=1,2$ are equally likely but now the proportions of early and late consumers differ across states:

$\begin{array}{ccc}\text { Proportion } & \text { State } 1 & \text { State } 2 \\ \text { Early consumers } & 0.4 & 0.6 \\ \text { Late consumers } & 0.6 & 0.4\end{array}$

By varying $r$ we can generate the same phenomena as in the case of return shocks. Rather than go through all the different cases, we illustrate a pure intermediated equilibrium for the case $r=1.6$. The equilibrium values are shown in Table 1. For this case the aggregate liquidity constraint binds in both states because the return on the long asset is high. At date 1 all the proceeds from the short asset are used for consumption. In state 1 aggregate liquidity needs are low at date 1 . Since consumption is split evenly among early consumers per capita consumption is high compared to state 2 where aggregate liquidity needs are high at date 1 . At date 2 there are many late consumers in state 1 so consumption per capita is lower than in state 2 where there are relatively few late consumers. 


\section{Complete participation and redundancy}

Cone (1983) and Jacklin (1986) have pointed out that the beneficial effects of banks in the Diamond-Dybvig (1983) model depend on the assumption individuals are not allowed to trade assets at the intermediate date. Increasing access to financial markets actually lowers welfare. If investors are allowed to participate in asset markets, then the market allocation weakly dominates the allocation implemented by the banks.

In this section, we show that with complete markets and complete market participation, banks are redundant in the sense that they cannot improve on the risk sharing achieved by markets alone. The ability of intermediaries to provide insurance against shocks to liquidity preference depends crucially on the assumption that investors cannot participate directly in asset markets. To show this, we first characterize an equilibrium with markets but without intermediaries. Then we show that the introduction of intermediaries is redundant.

The market data is the same as in Section 2. Investors are allowed to trade in markets for Arrow securities at date 0 and can trade in the spot markets for the good at date 1 . Let $y_{i}$ denote the portfolio chosen by a representative investor of type $i$ and let $x_{i}\left(\theta_{i}, \eta\right)$ denote the consumption bundle chosen by an investor of type $\theta_{i}$ in state $\eta$. The investor's choice of $\left(x_{i}, y_{i}\right)$ must solve the decision problem:

$$
\begin{array}{ll}
\max & \sum_{\eta} \sum_{\theta_{i}} \lambda\left(\theta_{i}, \eta\right) u_{i}\left(x_{i}\left(\theta_{i}, \eta\right), \theta_{i}\right) \\
\text { s.t. } & \sum_{\eta} q(\eta) \cdot x_{i}\left(\theta_{i}, \eta\right) \leq \sum_{\eta} q(\eta) p(\eta) \cdot\left(y_{i},\left(1-y_{i}\right) R(\eta)\right), \forall \theta_{i} .
\end{array}
$$

The maximization problem for the individual is similar to that of an intermediary of type $i$ except for two things. First, there is no explicit incentive constraint $x_{i} \in X_{i}$. Second, there is no insurance provided against the realization of $\theta_{i}$. This is reflected in the fact that, instead of summing the budget constraint over $\eta$ and $\theta_{i}$, it is summed over $\eta$ only and must be satisfied for each $\theta_{i}$. The ex ante type $i$ can redistribute wealth across states $\eta$ in any way he likes, but each type $\theta_{i}$ will get the same amount to spend in state $\eta$. As a result, for each realization of $\theta_{i}$ in a given state $\eta$, the choice of $x_{i}\left(\theta_{i}, \eta\right)$ must maximize the utility function $u_{i}\left(x_{i}\left(\theta_{i}, \eta\right), \theta_{i}\right)$ subject to a budget constraint that depends on $\eta$ but not on $\theta_{i}$. This ensures that incentive compatibility is satisfied.

An equilibrium for this economy consists of a price system $\{p, q\}$ and an attainable allocation $\left\{\left(x_{i}, y_{i}\right)\right\}$ such, that for every type $i,\left(x_{i}, y_{i}\right)$ solves the individual investor's problem above.

Comparing this definition of equilibrium with the intermediary equilibrium, it is clear that an equilibrium with complete market participation cannot implement the incentiveefficient equilibrium except in the special case where there are no gains from sharing risk against liquidity preference shocks.

The more interesting question is whether introducing intermediaries in this context can make investors any better off. The answer, as we have suggested, is negative. To see this, note first of all that in an equilibrium with complete participation, all that investors care about in each state is the market value of the bundle they receive from the intermediary. If an intermediary offers a mechanism $x_{i}$ the investors of type $\theta_{i}$ will report the ex post type $\hat{\theta}_{i}$ 
that maximizes $p(\eta) \cdot x_{i}\left(\hat{\theta}_{i}, \eta\right)$ in state $\eta$. Using the Revelation Principle, there is no loss of generality in assuming that the value of consumption $p(\eta) \cdot x_{i}\left(\theta_{i}, \eta\right)=w_{i}(\eta)$ is independent of $\theta_{i}$. But this means that the intermediary can do nothing more than replicate the effect of the markets for Arrow securities. More precisely, the intermediary is offering a security that pays $w_{i}(\eta)$ in state $\eta$ and the intermediary's budget constraint

$$
\sum_{\eta} q(\eta) w_{i}(\eta) \leq \sum_{\eta} q(\eta) p(\eta) \cdot\left(y_{i},\left(\mu_{i}-y_{i}\right) R(\eta)\right)
$$

ensures that $\left\{w_{i}(\eta)\right\}$ can be reproduced as a portfolio of Arrow securities at the same cost.

Theorem 3 In an equilibrium with complete market participation, the introduction of intermediaries is redundant in the sense that an equilibrium allocation in an economy with intermediaries is payoff-equivalent to (i.e., yields the same expected utilities as) an equilibrium allocation of the corresponding economy without intermediaries.

This is, essentially, a "Modigliani-Miller" result, saying that whatever an intermediary can do can be done (and undone) by individuals trading on their own in the financial markets. This result underlines the role of assuming incomplete participation. Given gains from sharing the risk of liquidity shocks that intermediaries provide, complete participation is undesirable.

Theorem 2 provides conditions under which an equilibrium will be incentive-efficient. However, the equilibrium described in Theorem 2 does not necessarily Pareto-dominate the equilibrium described in Theorem 3: with many ex ante types, it is possible that one type $i$ will be worse off in the incentive-efficient equilibrium. In the special case where there is a single ex ante type, complete participation makes everyone worse off. The results of Cone (1983) and Jacklin (1986) referred to earlier assume a single ex ante type of investor.

\section{$5 \quad$ Incomplete contracts and default}

In the benchmark model defined in Section 3, intermediaries use general, incentive-compatible contracts. In reality, we do not observe such complex contracts. There are many reasons for this which are well documented in the literature. These include transaction costs, asymmetric information and the nature of the legal system. These kinds of assumption can justify the use of debt and many other kinds of contracts that intermediaries use in practice. Since we are interested in developing a general framework we do not model any specific justification for incomplete contracts. Instead we assume that the contract incompleteness can take any form and prove results that hold for any type of incomplete contract.

With complete contracts, intermediaries can always meet their commitments. Default cannot occur. Once contracts are constrained to be incomplete, then it may be optimal for the intermediary to default in some states. In the event of default, it is assumed that the intermediary's assets, including the Arrow securities it holds, are liquidated and the proceeds distributed among the intermediary's investors. For markets to be complete, which 
is an assumption we maintain for the moment, the Arrow securities that the bank issues must be default free. Hence, we assume that these securities are collateralized and their holders have priority. Anything that is left after the Arrow securityholders have been paid off is paid out pro rata to the depositors.

An intermediary of type $i$ chooses a formal contract $x_{i} \in X_{i}^{I}$ and an indicator function $B: H \rightarrow\{0,1\}$, where $B(\eta)=1$ means that the intermediary defaults on the formal contract. There is also a 'default contract', which describes what happens when the intermediary defaults. The 'default contract' $\bar{x}_{i}$ is defined by $x\left(\theta_{i}, \eta\right)=\left(w_{i}(\eta), 0\right)$, where $w_{i}(\eta)$ is the liquidated value of assets in state $\eta$. The 'default contract' is not part of the formal contract; it is determined by the institution of bankruptcy (the nexus of law, courts, creditors and debtors) when the contract has been breached. Formally, it is possible to describe all this as a single mechanism, which is what we do, but conceptually there is an important difference between what the formal contract says and what happens if the formal contract is breached. The institution of bankruptcy is exogenous to the model, something the intermediary takes as given when writing the contract.

Given this bankruptcy procedure, an intermediary has to choose two contracts for individuals, a formal contract $x_{i} \in X_{i}^{I}$ and a default contract $\bar{x}_{i}$, and a decision rule $B: H \rightarrow\{0,1\}$ that indicates when the bank defaults. Then the effective contract $\hat{x}_{i}$ is defined by

$$
(1-B(\eta)) x_{i}\left(\theta_{i}, \eta\right)+B(\eta) \bar{x}_{i}\left(\theta_{i}, \eta\right)
$$

for every $\left(\theta_{i}, \eta\right)$. Since everything is paid out at date 1 in the event of default, investors use the short asset to provide consumption at date 2 . Then the utility of a contract $x_{i}$ generated in this way is given by $u_{i}^{*}\left(x_{i}\left(\theta_{i}, \eta\right), \theta_{i}\right)$ in the state $\left(\theta_{i}, \eta\right)$ and the incentive constraint is

$$
u_{i}^{*}\left(x_{i}\left(\theta_{i}, \eta\right), \theta_{i}\right) \geq u_{i}^{*}\left(x_{i}\left(\hat{\theta}_{i}, \eta\right), \theta_{i}\right), \forall \theta_{i}, \hat{\theta}_{i} \in \Theta_{i}
$$

Let $\hat{X}_{i}$ denote the set of incentive-compatible contracts generated in this way.

To demonstrate how default works consider the following simple illustration.

Example Suppose that intermediaries are restricted to offering non-contingent contracts. Then $x_{i} \in X^{I}$ if and only if

$$
x_{i}\left(\theta_{i}, \eta\right)=x_{i}\left(\theta_{i}, \eta^{\prime}\right)
$$

for any $\eta, \eta^{\prime} \in H$. If we assumed further that agents were either early consumers, who value consumption at date 1 , or late consumers who value consumption at date 2 , we could without loss of generality write the contract as

$$
x_{i}\left(\theta_{i}, \eta\right)= \begin{cases}\left(c_{1}, 0\right) & \text { if } \theta_{i}=0 \\ \left(0, c_{2}\right) & \text { if } \theta_{i}=1 .\end{cases}
$$

This contract is highly inflexible because it does not allow the intermediary to adjust the payment across states in response to changing demands for liquidity or changing asset returns. If default is not allowed, the intermediary is forced to distort the contract. Default 
allows the intermediary to replace this inflexible contract with the following:

$$
\hat{x}_{i}\left(\theta_{i}, \eta\right)=\left\{\begin{array}{cc}
\left(c_{1}, 0\right) & \text { if } \theta_{i}=0, B_{i}(\eta)=0 \\
\left(0, c_{2}\right) & \text { if } \theta_{i}=1, B_{i}(\eta)=0 \\
\left(w_{i}(\eta), 0\right) & \text { if } B_{i}(\eta)=1 .
\end{array}\right.
$$

The possibility of incomplete contracts is represented by restricting the choice of contract to a subset $\hat{X}_{i} \subset X_{i}$. The theory developed in Section 3 is essentially the same, but with $X_{i}$ replaced by $\hat{X}_{i}$. With this substitution, an intermediated equilibrium becomes an intermediated equilibrium with incomplete contracts, an incentive-efficient allocation becomes a constrained-efficient equilibrium, and Assumption 2 becomes Assumption 2'. Then Theorem 2 can be interpreted as a theorem about constrained-efficiency of equilibrium with incomplete contracts but complete markets.

Theorem 4 Under the maintained assumptions, if $(p, q, x, y)$ is an intermediated equilibrium with incomplete contracts and Assumption $2^{\prime}$ is satisfied, then the allocation $(x, y)$ is constrained-efficient.

Although this result is a direct corollary of Theorem 2, it is substantively the most important result of the paper, for it shows that, in the presence of complete markets, the incidence of default is optimal in a laisser-faire equlibrium. For example, consider the case where banks are restricted to using demand deposits that promise a fixed payment at date 1. A bank may default in some states because its assets are insufficient to meet its noncontingent commitments. Default allows the bank to make its risk-sharing contract more contingent, i.e., more complete. But if several banks default in the same state, this may cause a financial crisis, as the simultaneous liquidation of several banks forces down asset prices, which may in turn cause distress in other banks. Nonetheless, the theorem shows that, given complete markets for insuring against aggregate shocks, the occurence of these crises is optimal and not a market failure. There is no scope for welfare-improving government intervention to prevent financial crises.

Remark: The definition of constrained efficiency is formally similar to the definition of incentive-efficiency - we simply substitute $\hat{X}$ for $X$ in the latter - but there are important substantive differences. The definition of $\hat{X}$ implicitly incorporates the "bankruptcy code" and requires consumers to be autarkic once the intermediary defaults. Allowing trade after default would complicate the theory but should not change the basic result as long as markets for aggregate risk are incomplete.

Remark: Alonso (1996) and Allen and Gale (1998) have argued that financial crises can sometimes be optimal, or at least Pareto-preferred to government intervention to suppress crises entirely. While these arguments have a similar flavor to the present results, they are substantially different. Both Alonso (1996) and Allen and Gale (1998) rely on very special examples to show that laisser faire may be preferred to a policy of preventing financial crises. There is no general efficiency result. In fact, Allen and Gale (1998) show that even within the context of their example, the efficiency of financial crises is not robust. 
More importantly, there is no role for Arrow securities in the examples provided by Alonso (1996) and Allen and Gale (1998). In their models, a representative bank chooses a portfolio and deposit contract to maximize the expected utility of the representative agent. Because of the representative agent assumption, banks are autarkic and complete markets are irrelevant. So the results presented here are based on a different argument and apply to a much broader class of economies.

Remark: The role of Arrow securities deserves further attention in a model with default. An Arrow security is a promise to deliver one unit of the good in some state at date 1. It is assumed, crucially, that Arrow securities are fully collateralized so there is no risk of default on these promises. Equivalently, traders in Arrow securities can anticipate each intermediary's ability to repay borrowing through Arrow securities in each state and Arrow securities take priority over other claims on the intermediary's assets. This means that, at date 0 , the intermediary will not be allowed to execute trades that cannot be fulfilled at date 1 and that the intermediary's position in Arrow securities is settled at the beginning of date 1 before anything else happens, in particular, before the default decision is made and before investors receive any payments. These assumptions are restrictive but they are essential to the definition of Arrow security markets.

Remark: Default is completely voluntary in the sense that the intermediary chooses at date 0 those states in which it wishes to default. Default is not forced on the intermediary by the budget constraint, in fact, in the presence of complete markets it is not clear what this would mean. Because Arrow security markets are complete, there is a single budget constraint and the intermediary chooses the amount of wealth allocated to each state. We do however assume that the intermediary is committed to his default decision at date 0 and further, that he makes the default decision in the ex ante interest of the representative investor. These assumptions are restrictive but interesting insofar as they are required for efficiency. We can interpret them as a description of an optimal bankruptcy institution.

\subsection{Examples}

In this section we demonstrate a number of results using examples. These results include the following.

1. The existence (indeed necessity) of mixed equilibria.

2. The optimality of default and crises.

3. Cash-in-the-market pricing when there is a crisis.

4. Suboptimal risk sharing with incomplete markets.

There are many examples of intermediaries that use incomplete contracts with their depositors. As we have seen, as soon as incomplete contracts are introduced the possibility of default must be allowed for. This in turn introduces the possibility of financial crises. In practice crises can be precipitated by a wide array of intermediaries. Historically, however, it 
has been banks that have caused most crises. In order to illustrate the model with incomplete contracts and default we consider examples where the intermediaries are banks, that is, they are restricted to issuing deposit contracts. A deposit contract promises a fixed payment at date 1. If the bank is unable to meet its commitment to its depositors, then it is liquidated and all its assets are sold. If it can meet its commitment depositors can keep their funds in the bank until date 2 .

Example 4. To illustrate the properties of a banking equilibrium, we revert to the parameters from Example 1.

Example 4A. For $r \geq 1$ the first best can again be implemented as a banking equilibrium. The first-best allocation requires that consumption at date 1 be the same in both states, so the optimal incentive-compatible contract is in fact a deposit contract. Moreover, bankruptcy does not occur in equilibrium. The allocation corresponding to a pure banking equilibrium is exactly the same as the allocation corresponding to a pure intermediated equilibrium, which as we have seen is the same as the first best. For $r=1.5$, for example, the equilibrium values will be the same as for Example 1A, as shown in Table 1.

The main difference between Examples $1 \mathrm{~A}$ and $4 \mathrm{~A}$ is that the prices supporting the first best allocation are unique in Example 1A but are not in Example 4A. In Example 1A the general intermediaries can freely vary payoffs across states and dates so only one set of prices can support the optimal allocation. Because the banks are restricted to using deposit contracts in Example 4A, consumption at date 1 is independent of the state as long as there is no bankruptcy. This prevents the banks from arbitraging between the states at date 1 . In effect, we have lost one equilibrium condition compared with the intermediated equilibrium. Any vector of prices $\left(q(1), q(2), p_{2}(1), p_{2}(2)\right)$ that supports the equilibrium allocation at date 2 is consistent with a banking equilibrium. The following no-arbitrage conditions are satisfied

$$
\begin{aligned}
q(1) p_{2}(1) & =0.33 \\
q(2) p_{2}(2) & =0.25 \\
q(1)+q(2) & =1
\end{aligned}
$$

and the existence of the short asset implies that

$$
p_{2}(1) \leq 1 ; p_{2}(2) \leq 1
$$

Combining these conditions, it follows that the range of possible prices for $q(1)$ is

$$
0.33 \leq q(1) \leq 0.75
$$

The other prices are determined by (9)-(11).

For $r<1$ deposit contracts cannot be used to implement the first best or incentiveefficient allocation. In particular, a deposit contract that is consistent with the incentiveefficient consumption in state 2 would imply bankruptcy in state 1 (see, e.g., Example 1B). If all banks were to offer a contract which allowed bankruptcy in state 1 they would all be 
forced to liquidate their assets. If they all do this, there is no bank on the other side of the market to buy the assets and the price of future consumption, $p_{2}(1)$, falls to 0 . This cannot be an equilibrium because it would be worthwhile for an individual bank to offer a contract which did not involve bankruptcy. This bank could then buy up all the long term asset in state 1 at date 1 for $p_{2}(1)=0$ and make a large profit.

This argument indicates that for $r<1$ there cannot be a pure banking equilibrium with bankruptcy. There are two other possibilities. One is that there is a pure equilibrium in which all banks remain solvent. The other is that there is a mixed equilibrium in which banks choose different contracts and portfolios. In particular, a group of banks with measure $\rho$ makes choices that allow it to remain solvent in state 1 while the remaining $1-\rho$ banks go bankrupt. The banks that are ensured of solvency are denoted type $S$ while those that can go bankrupt are denoted type $B$. It turns out that both the pure equilibrium with all banks remaining solvent and the mixed equilibrium can occur when $r<1$.

Example 4B. For $0.90 \leq r<1$ there is a pure banking equilibrium in which all the banks choose to remain solvent $(\rho=1)$. There is again a range of prices which can support the allocation. Type- $S$ banks stay solvent by lowering the amount promised at date 1 , lowering their investment in the short asset and increasing their investment in the long asset. The equilibrium values for the case where $r=0.95$ are shown in Table 1 . The range of $q(1)$ that will support the allocation and prevent entry by type $B$ banks is $0.55<q(1)<0.77$. The other prices are determined by the equilibrium conditions

$$
\begin{aligned}
q(1) p_{2}(1) & =0.54 \\
q(2) p_{2}(2) & =0.24 \\
q(1)+q(2) & =1 .
\end{aligned}
$$

Example 4C. For $0<r<0.90$ there exists a mixed banking equilibrium. At the boundary $r=0.90$, the set of prices that will support the equilibrium of the type shown in Example $4 \mathrm{~B}$ shrinks to a singleton: $(q(1)=2 / 3, q(2)=1 / 3)$. For values of $r<0.90$ but close to 0.90 the proportion of type- $S$ banks is large $(\rho \approx 1)$. As $r$ falls, the proportion of type- $B$ banks rises until as $r$ goes to 0 the proportion of type- $B$ banks $1-\rho$ approaches 1 . The mixed banking equilibrium corresponding to $r=0.5$ is shown in Table 1. The proportion of type- $S$ banks is $\rho=0.35$. As in the earlier examples, the portfolios of individual banks are indeterminate. It is only the aggregate portfolio that is determined by the equilibrium conditions.

The pricing of assets in state 1 in Example $4 \mathrm{C}$ illustrates the principle of "cash-in-themarket pricing". When the type- $B$ banks go bankrupt in state 1 they have to liquidate all their holdings of the long asset. These are purchased by the type- $S$ banks who use all of their spare liquidity to do so. In making the decision on how much of the short asset to hold they trade off the benefits of liquidity in the low output state with the cost of holding idle funds in the high output state. 
The effect of cash-in-the-market pricing can be seen if we compare this example with Example 1B. The price of the long asset is $0.5 \times 1=0.5$ in Example $1 \mathrm{~B}$ and $0.5 \times 0.9=0.45$ in the present example. It can easily be shown that the price of the long asset could be depressed further by changing the parameters. For example, the lower the probability of the low-output state, the less liquidity the type- $S$ bank will hold and the lower the price of the long asset will be in the low-output state.

The mixed equilibrium in Example $4 \mathrm{C}$ illustrates a number of interesting phenomena. First, banks serving identical depositors may do quite different things in equilibrium. One subset will find it optimal to follow a safe strategy and avoid the risk of bankruptcy. Another subset will follow a risky strategy that makes bankruptcy inevitable in state 1. As a result, even when all investors are identical ex ante, there can be a financial crisis in which some banks remain solvent while others go under. In the context of the example, the crisis is more severe when the state- 1 return $r$ is lower. However, the results in Section 5 show that these crises are consistent with the constrained efficiency of equilibrium. There is no justification for intervention or regulation of the financial system. A planner could not do better.

Many analyses of banking assume that there is a technology for early liquidation of the long term asset. The resulting equilibria are typically symmetric. This example illustrates that this assumption materially changes the form of the equilibrium. With endogenous liquidation one group of banks must provide liquidity to the market and this results in mixed equilibria.

A comparison of Example 4C with Example 1 shows the importance of non-contingent contracts in causing financial crises. In Example 1 the ability to use state contingent contracts with investors means that bankruptcy never occurs and as a result there is never a crisis. However, with deposit contracts crises of varying severity always occur in the low output state.

There are a number of other types of equilibrium, depending on whether the short asset is held between date 1 and date 2 and the number of ex ante groups. The properties of these equilibria are similar to those illustrated in Examples 1 and 2 and will not be repeated here.

In Example 4 it was assumed that markets are complete. However, it can straightforwardly be seen that with incomplete markets the allocation in each case would be the same. In Examples $4 \mathrm{~A}$ and $4 \mathrm{~B}$ there is only one ex ante type in equilibrium and they all do the same thing so the open interest in Arrow securities is zero and there is no role for risk sharing. In the mixed equilibrium of Example $4 \mathrm{C}$ there are two types of banks providing different allocations even though ex ante all investors are identical. Complete markets do not help risk sharing, however. The reason is that the contract forms restrict the amounts that can be paid out and the trade-offs given these mean that no improvement can be made. The only difference in Example 4C if markets are incomplete is the equilibrium holdings of assets of the two banks are now unique. The type- $S$ banks hold 0.82 of the short asset and the type- $B$ banks hold 0.59 of it. This fact that complete markets does not make a difference here is clearly a special case as the next example, which mixes Example 2 and Example 4C, demonstrates. 
Example 5A. The example is the same as Example 2 except that contracts are incomplete. There are risk averse type- $A$ investors and risk neutral type- $N$ investors, $r=0.5$ and there are complete Arrow security markets. It can straightforwardly be seen that the equilibrium is exactly the same as that shown in Table 1 for Example 2. The type- $A$ banks can use a deposit contract promising 1 at date 1 to implement the optimal allocation. Similarly the type- $N$ banks can use a deposit contract promising 0 at date 1.

Example 5B. This example is the same as Example 5A except now there are no Arrow securities so markets are incomplete. Here it can be seen that the equilibrium is essentially the same as in Example 4C. The banks for the type- $A$ investors behave exactly as in Example $4 \mathrm{C}$. The banks for the type- $N$ investors do not find it worthwhile to enter the markets that do exist. They simply put all their customers endowment in the long asset and pay out 0 at date 1 and whatever is produced at date 2 .

A comparison of Examples 5A and 5B demonstrates the crucial role that complete markets can play. With complete markets the financial system produces the first best allocation. However, with incomplete markets the allocation is much worse. Moreover the incompleteness of markets leads to default and crises in equilibrium.

In conclusion, the examples in this section have demonstrated the results mentioned initially. First, Example $4 \mathrm{C}$ has shown that a mixed equilibrium can exist. When there is only one type of bank they cannot all go bankrupt at the same time. If they did there would be nobody to buy their assets and the assets' price would fall to 0 . This cannot be an equilibrium though since it would be worthwhile for a bank to stay solvent and buy up all the assets at the 0 price. As a result the equilibrium must be mixed.

Second, Example 4C shows that default can be optimal for the banks. Theorem 4 shows that the crises that result from banks' defaulting are also socially optimal. In fact crises are necessary for the constrained-efficient allocation to be achieved.

Third, the logic demonstrating the existence of mixed equilibria shows how cash-in-themarket pricing occurs. In making their decision on how much of the short asset to hold, the solvent banks take into account the fact that if there is a crisis they can buy up the long asset cheaply and trade this off against the cost of not investing in the long asset at date 0 and rolling over the liquidity in state 2 .

Fourth, Example 5 demonstrates the important role of complete markets. With incomplete markets the equilibrium is completely different from the one with complete markets. Not only is risk sharing much better with complete markets but also there are no crises.

\section{Incomplete markets and liquidity regulation}

The absence of markets for insuring individual liquidity shocks does not by itself lead to market failure. As we showed in Section 3, intermediaries with complete contracts can achieve an incentive-efficient allocation of risk under certain conditions. We showed in Section 5, under the same conditions, that intermediaries with incomplete contracts can 
achieve a constrained-efficient allocation of risk. Two assumptions are crucial for these results: markets for aggregate uncertainty are complete (there is an Arrow security for each state $\eta$ ) and market participation is limited. Markets for aggregate risk allow intermediaries to share risk among different ex ante types of investor and limited participation allows intermediaries to offer insurance against the realization of ex post types.

In order to generate a market failure and provide some role for government intervention, an additional friction must be introduced. Here we assume that it comes in the form of incomplete markets for aggregate risk. There are two sources of aggregate risk in this model. One is the return to the risky asset $R(\eta)$; the other is the distribution of investors' liquidity preferences $\lambda\left(\theta_{i}, \eta\right)$. Although there is a continuum of investors, correlated liquidity shocks give rise to aggregate fluctuations in the demand for liquidity.

Market incompleteness may be expected to vary according to the source of the risk. On the one hand, asset returns can be hedged using markets for stock and interest rate options and futures. For example, financial markets allow intermediaries to take hedging positions on future asset prices and interest rates. Additional hedges can be synthesized using dynamic trading strategies. On the other hand, liquidity shocks seem harder to hedge. Asset prices and interest rates are functions of the aggregate distribution of liquidity shocks in the economy. Inverting this relationship, we can use asset prices and interest rates to infer the average demand for liquidity, but not the liquidity shock experienced by a particular intermediary. Hence, trading options and futures will not allow intermediaries to provide insurance against their own liquidity shocks. So markets for hedging liquidity shocks are likely to be more incomplete than the markets for hedging asset returns.

We analyze a polar case below: we assume that there exist complete markets for hedging asset return shocks, but no markets for hedging liquidity shocks. Since complete markets for asset-return shocks permit efficient sharing of that risk, we might as well assume that asset returns are non-stochastic. In what follows, we adopt the simplifying assumption that the return to the long asset is a constant $r>1$ and the only aggregate uncertainty comes from liquidity shocks.

We continue to assume that each intermediary serves a single type of investor. Let $x_{i}$ denote the mechanism and $y_{i}$ the portfolio chosen by the representative intermediary of type $i$. The problem faced by the intermediary is to choose $\left(x_{i}, y_{i}\right)$ to maximize the expected utility of the representative depositor subject to multiple, state-contingent budget constraints:

$$
\begin{array}{ll}
\max & \sum_{\eta} \sum_{\theta_{i}} \lambda\left(\theta_{i}, \eta\right) u_{i}\left(x_{i}\left(\theta_{i}, \eta\right), \theta_{i}\right) \\
\text { s.t. } & x_{i} \in X_{i} ; \\
& \sum_{\theta_{i}} \lambda\left(\theta_{i}, \eta\right) p(\eta) \cdot x_{i}\left(\theta_{i}, \eta\right) \\
& \leq p(\eta) \cdot\left(y_{i},\left(\mu_{i}-y_{i}\right) R(\eta)\right), \forall \eta .
\end{array}
$$

The incompleteness of markets is reflected in the fact that there is a separate budget constraint for each aggregate state of nature $\eta$, rather than a single budget constraint that integrates surpluses and deficits across all states.

With incomplete markets, the existence of welfare-improving interventions is well known in many contexts (cf. Geanakoplos and Polemarchakis (1986)). Rather than pursuing general 
inefficiency results, we investigate a more specific policy intervention: Is there too much or too little liquidity in a laisser-faire equilibrium? The interest of the results follows not from the existence of a policy that increases welfare, but rather from the precise characterization of the optimal (small) intervention to regulate liquidity. Our intuition suggests that market provision of liquidity will be too low when markets are incomplete. However, even in an equilibrium with a lot of structure, our analysis shows that whether there is too much or too little liquidity depends crucially on the degree of relative risk aversion.

We identify liquidity regulation with manipulation of portfolio choices at the first date. For example, a lower bound on the amount of the short asset held by intermediaries can be interpreted as a reserve requirement. We examine regulation in the context of an economy with Diamond-Dybvig preferences.

As usual, there are $n$ ex ante types of investors $i=1, \ldots, n$. The ex ante types are symmetric and the size of each type is normalized to $\mu_{i}=1$. There are two ex post types, called early consumers and late consumers. Early consumers only value consumption at date 1 , while late consumers only value consumption at date 2 . The ex ante utility function of type $i$ is defined by

$$
u_{i}\left(c_{1}, c_{2}, \theta_{i}\right)=\left(1-\theta_{i}\right) U\left(c_{1}\right)+\theta_{i} U\left(c_{2}\right),
$$

where $\theta_{i} \in\{0,1\}$. The period utility function $U: \mathbf{R}_{+} \rightarrow \mathbf{R}$ is twice continuously differentiable and satisfies the usual neoclassical properties, $U^{\prime}(c)>0, U^{\prime \prime}(c)<0$, and $\lim _{c \backslash 0} U^{\prime}(c)=\infty$.

Each intermediary is characterized at date 1 by the proportions of early and late consumers among its customers. Call these proportions the intermediary's type. Then aggregate risk is characterized by the distribution of types of intermediary at date 1 . We assume that the cross-sectional distribution of types is constant and no variation in the total demand for liquidity. In this sense there is no aggregate uncertainty. However, individual intermediaries receive different liquidity shocks: some intermediaries will have high demand for liquidity and some will have low demand for liquidity. The asset market is used to re-allocate liquidity from intermediaries with a surplus of liquidity to intermediaries with a deficit of liquidity. It is only the cross-sectional distribution of liquidity shocks that does not vary. To make this precise, we need additional notation. We identify the state $\eta$ with the $n$-tuple $\left(\eta_{1}, \ldots, \eta_{n}\right)$, where $\eta_{i}$ is the fraction of investors of type $i$ who are early consumers in state $\eta$. The fraction of early consumers takes a finite number of values, denoted by $0<\sigma_{k}<1$, where $k=1, \ldots, K$. We assume that the marginal distribution of $\eta_{i}$ is the same for every type $i$ and that the cross-sectional distribution is the same for every state $\eta$. Formally, let $\lambda_{k}$ denote the ex ante probability that the proportion of early consumers is $\sigma_{k}$. Let $H_{i k}=\left\{\eta \in H: \eta_{i}=\sigma_{k}\right\}$. Then $\lambda_{k}=\sum_{\eta \in H_{i k}} \lambda_{i}(0, \eta)$, for every $k$ and every type $i$. Ex post, $\lambda_{k}$ equals the fraction of ex ante types with a proportion $\sigma_{k}$ of early consumers. Then $\lambda_{k}=n^{-1} \#\left\{i: \eta_{i}=\sigma_{k}\right\}$, for every $k$ and every state $\eta$.

The return on the long asset is non-stochastic,

$$
R(\eta)=r>1, \forall \eta
$$

The only aggregate uncertainty in the model relates to the distribution of liquidity shocks across the different ex ante types $i$. 
In what follows, we focus on symmetric equilibrium, in which the prices at dates 1 and 2 are independent of the realized state $\eta$ and the choices of the intermediaries at date 0 are independent of the ex ante type $i$. Let the good at date 1 be the numeraire and let $p$ denote the price of the good at date 2 in terms of the good at date 1 . At date 0 the representative intermediary of type $i$ chooses a portfolio $y_{i}=y$ and a consumption mechanism $x_{i}(\eta)=x\left(\eta_{i}\right)$ to solve the following problem:

$$
\begin{array}{ll}
\max & \sum_{k} \lambda_{k}\left\{\sigma_{k} U\left(x_{1}\left(\sigma_{k}\right)\right)+\left(1-\sigma_{k}\right) U\left(x_{2}\left(\sigma_{k}\right)\right)\right\} \\
\text { s.t. } & \sigma_{k} x_{1}\left(\sigma_{k}\right)+\left(1-\sigma_{k}\right) p x_{2}\left(\sigma_{k}\right) \leq y+\operatorname{pr}(1-y), \forall k, \\
& x_{1}\left(\sigma_{k}\right) \leq x_{2}\left(\sigma_{k}\right), \forall k .
\end{array}
$$

The incentive constraint $x_{1}\left(\sigma_{k}\right) \leq x_{2}\left(\sigma_{k}\right)$ is never binding. To see this, drop the incentive constraint and solve the relaxed problem. The special early-consumer, late-consumer structure of preferences and the assumption $r>1$ imply that the incentive constraint is automatically satisfied by the solution to the relaxed problem.

A symmetric equilibrium consists of an array $(p, x, y)$ such that $(x, y)$ solves the problem (12) for the equilibrium price $p$ and the market-clearing conditions

$$
\begin{aligned}
& \sum_{k=1}^{K} \lambda_{k} \sigma_{k} x_{1}\left(\sigma_{k}\right) \leq y \\
& \sum_{k=1}^{K} \lambda_{k}\left\{\sigma_{k} x_{1}\left(\sigma_{k}\right)+\left(1-\sigma_{k}\right) x_{2}\left(\sigma_{k}\right)\right\}=y+r(1-y) .
\end{aligned}
$$

are satisfied.

To study the effect of regulation of intermediaries, we take as given the choice of portfolio $y$ at date 0 and consider the determination of the consumption mechanism $x$ and the marketclearing price $p$. Call $(p, x, y)$ a regulated equilibrium if $x$ solves the problem (12) for the given values of $p$ and $y$, and $(x, y)$ satisfies the market-clearing conditions (15).

Suppose that $(p, x, y)$ is a regulated equilibrium and $p>p^{*}$. Then the short asset is dominated by the long asset between dates 0 and 1 and no one will want to hold the short asset. If the regulator requires intermediaries to hold a minimum amount of the short asset then each intermediary will want to hold the minimum. In that case, $(x, y)$ solves the maximization problem (12) subject to the additional constraint $y \geq \bar{y}$ for an appropriately chosen value of $\bar{y}$. Similarly, if $p<p^{*}$ then the long asset is dominated and $(x, y)$ solves the maximization problem subject to an additional constraint $y \leq \bar{y}$. Thus, any regulated equilibrium can be interpreted as an equilibrium in which the intermediaries choose the mechanism $x$ and the portfolio $y$ to maximize the expected utility of the depositors subject to a constraint that requires them to hold a minimum amount of the short asset in the case $p>p^{*}$ or of the long asset in the case $p<p^{*}$. In this sense, the regulator can implement the regulated equilibrium $(p, x, y)$ by imposing an appropriate constraint $\bar{y}$ on the intermediaries' portfolio choice.

By manipulating the intermediaries' portfolio choice, the regulator is able to manipulate the equilibrium price $p$. The welfare effect of this change in price depends on the degree of risk aversion. We can state a positive result for regulatory policy as follows: it is possible to increase welfare by imposing a lower bound on intermediaries' holdings of the short asset if 
the degree of relative risk aversion is greater than one. More precisely, let $W(p)$ denote the expected utility of the typical depositor in the regulated equilibrium $(p, x, y)$.

Theorem 5 If $\left(p^{*}, x^{*}, y^{*}\right)$ is a symmetric equilibrium and $-U^{\prime \prime}(c) c / U^{\prime}(c)>1$, then for some $\bar{y}>y^{*}$ there is a regulated equilibrium $(p, x, y)$ in which intermediaries are required to hold at least $\bar{y}$ units of the short asset and $W(p)>W\left(p^{*}\right)$.

The proof of this result is in Section 8. The key step in the argument is provided by the following lemma, which shows how the degree of risk aversion determines the welfare effect of a change in the regulated equilibrium price.

Lemma 6 For any $p>p^{*}$ sufficiently close to $p^{*}, W(p)>W\left(p^{*}\right)$ if

$$
-\frac{U^{\prime \prime}(c) c}{U^{\prime}(c)}>1 .
$$

For any $p<p^{*}$ sufficiently close to $p^{*}, W(p)>W\left(p^{*}\right)$ if

$$
-\frac{U^{\prime \prime}(c) c}{U^{\prime}(c)}<1 .
$$

Proof. See Section 8.

So an increase in liquidity (increase in the price of the long asset) may increase or decrease welfare, depending on the degree of risk aversion.

The intuition behind this result is the following. When relative risk aversion is high, optimal risk sharing requires that consumption at date 1 is higher than the present value of consumption at date 2 , that is, $c_{1}>p c_{2}$. An increase in the fraction of early consumers $\sigma$, cet. par., implies an increase in the present value of total consumption $\sigma c_{1}+(1-\sigma) p c_{2}$. In order to satisfy the budget constraint,

$$
\sigma c_{1}+(1-\sigma) p c_{2}=y+\operatorname{pr}(1-y)
$$

both $c_{1}$ and $c_{2}$ must fall (efficient risk-sharing implies that $c_{1}$ and $c_{2}$ always rise and fall together). Then $(1-\sigma) c_{2}$, the total consumption at date 2 , falls and the budget constraint implies that $\sigma c_{1}$, the total demand for liquidity at date 1, rises. So per capita consumption at dates 1 and 2 and demand for liquidity go in opposite directions. From this it follows that, when $\sigma$ is high, $\sigma c_{1}>y$ and $(1-\sigma) c_{2}<r(1-y)$, so an increase increase in liquidity (increase in $p$ ), has a positive income effect and raises consumption and, when $\sigma$ is low, an increase in liquidity has the opposite effect. Thus, an increase in liquidity lowers consumption in good states (where per capita consumption is high) and raises it in bad states (where per capita consumption is low). This transfer from high-consumption states to low-consumption states raises welfare. When relative risk aversion is low, the argument works in the opposite direction. The welfare effect depends on the correlation between equilibrium consumption and the liquidity shocks. 


\section{Concluding Remarks}

We have argued that, contrary to the conventional wisdom, it is not axiomatic that financial crises are bad from a welfare point of view. In fact, we have presented conditions under which they are essential for constrained efficiency. This should give economists pause for thought. Although the conditions for efficiency are restrictive, they are no more so than the conditions usually required for efficiency of general equilibrium. We should also note that, while the focus of this paper is on a rudimentary model of banks and financial intermediaries, the basic ideas have a wider application. Wherever incompletely contingent contracts, such as debt contracts, are used, there is the possibility of default. In the absence of complete markets for the aggregate risks involved, financial crises in the form of widespread default may constitute a market failure requiring some form of intervention by the financial regulator.

The model we have used is special in several respects. For example, we have assumed that investors are condemned to autarky after a default. A more realistic model would allow intermediaries to enter and offer deposit contracts to investors whose intermediaries have defaulted at date 1 . We have seen, in Section 4, that incentive-efficient risk sharing requires limited participation in markets. In particular, we cannot allow investors to deal with more than one bank at a time. If investors could deal with a second bank ex post, this could undermine the incentive constraints in the original contract and result in lower welfare. However, once an intermediary has defaulted, there is no reason to prevent investors from accepting contracts with the surviving intermediaries and thus avoiding the inefficiency that arises from being excluded from asset markets. This would be more complicated, but would not fundamentally alter the results, as long as entry occurs after the original intermediary has defaulted and liquidated its assets.

Although we have tried to lay the groundwork for a welfare analysis of financial crises, we have only scratched the surface as far as the study of optimal regulation of the financial system is concerned. In particular, the role of central banking requires a much richer model of the monetary system and monetary policy. We have also avoided analyzing aggregate uncertainty in the context of incomplete markets and the possible role this provides for the central bank as a lender of last resort. We have not explored the interaction of the financial sector and the real sector, which is where the impact of financial crises is largely felt (Bernanke and Gertler (1989)).

These are all clearly subjects for future work.

\section{Proofs}

\subsection{Proof of Theorem 2}

The argument follows the lines of the familiar proof of the first fundamental theorem of welfare economics. Let $(x, y, p, q)$ be an equilibrium and suppose, contrary to what we want to show, that there is an attainable mixed allocation $\left\{\left(\rho^{j}, x_{i}^{j}, y_{i}^{j}\right)\right\}$ that makes some ex ante types better off and none worse off. If type $(i, j)$ is (strictly) better off under the new 
allocation then clearly

$$
\sum_{\eta} q(\eta) \sum_{\theta_{i}} \lambda\left(\theta_{i}, \eta\right) p(\eta) \cdot x_{i}^{j}\left(\theta_{i}, \eta\right)>\sum_{\eta} q(\eta) p(\eta) \cdot\left(y_{i}^{j},\left(\mu_{i}-y_{i}^{j}\right) R(\eta)\right)
$$

or $\left(x_{i}^{j}, y_{i}^{j}\right)$ would have been chosen. The next thing to show is that for every ex ante type $(i, j)$

$$
\sum_{\eta} q(\eta) \sum_{\theta_{i}} \lambda\left(\theta_{i}, \eta\right) p(\eta) \cdot x_{i}^{j}\left(\theta_{i}, \eta\right) \geq \sum_{\eta} q(\eta) p(\eta) \cdot\left(y_{i}^{j},\left(\mu_{i}-y_{i}^{j}\right) R(\eta)\right) .
$$

If not, then by Assumption 2 it is possible to find a feasible mechanism $x_{i}^{\prime}$ such that $\left(x_{i}^{\prime}, y_{i}^{j}\right)$ satisfies the budget constraint and makes type $i$ (strictly) better off than $\left(x_{i}, y_{i}\right)$, contradicting the definition of equilibrium. Then summing the budget constraints for all types $(i, j)$ we have

$$
\sum_{i, j} \rho^{j} \sum_{\eta} q(\eta) \sum_{\theta_{i}} \lambda\left(\theta_{i}, \eta\right) p(\eta) \cdot x_{i}^{j}\left(\theta_{i}, \eta\right)>\sum_{i, j} \rho^{j} \sum_{\eta} q(\eta) p(\eta) \cdot\left(y_{i}^{j},\left(\mu_{i}-y_{i}^{j}\right) R(\eta)\right)
$$

or

$$
\sum_{\eta} q(\eta) p(\eta) \cdot \sum_{i, j} \sum_{\theta_{i}} \lambda\left(\theta_{i}, \eta\right) \rho^{j} x_{i}^{j}\left(\theta_{i}, \eta\right)>\sum_{\eta} q(\eta) p(\eta) \cdot \sum_{i, j} \rho^{j}\left(y_{i}^{j},\left(\mu_{i}-y_{i}^{j}\right) R(\eta)\right) .
$$

The market-clearing conditions imply that, for each state $\eta$, either

$$
\sum_{i} \sum_{\theta_{i}} \lambda\left(\theta_{i}, \eta\right) \sum_{j} \rho^{j} x_{i}^{j}\left(\theta_{i}, \eta\right)=\sum_{i} \sum_{j} \rho^{j}\left(y_{i}^{j},\left(\mu_{i}-y_{i}^{j}\right) R(\eta)\right)
$$

if all the good is consumed at date 1 , or $p_{1}(\eta)=p_{2}(\eta)$ and

$$
\sum_{i, j} \sum_{\theta_{i}} \lambda\left(\theta_{i}, \eta\right) \rho^{j}\left(x_{i 1}^{j}\left(\theta_{i}, \eta\right)+x_{i 2}^{j}\left(\theta_{i}, \eta\right)\right)=\sum_{i, j} \rho^{j}\left(y_{i}^{j}+\left(\mu_{i}-y_{i}^{j}\right) R(\eta)\right)
$$

if some of the good is stored until date 2. In either case,

$$
p(\eta) \cdot \sum_{i, j} \sum_{\theta_{i}} \lambda\left(\theta_{i}, \eta\right) \rho^{j} x^{j}\left(\theta_{i}, \eta\right)=p(\eta) \cdot \sum_{i, j} \rho^{j}\left(y_{i}^{j},\left(\mu_{i}-y_{i}^{j}\right) R(\eta)\right) .
$$

Multiplying this equation by $q(\eta)$ and summing over $\eta$ yields

$$
\sum_{\eta} q(\eta) p(\eta) \cdot \sum_{i, j} \sum_{\theta_{i}} \lambda\left(\theta_{i}, \eta\right) \rho^{j} x^{j}\left(\theta_{i}, \eta\right)=\sum_{\eta} q(\eta) p(\eta) \cdot \sum_{i, j} \rho^{j}\left(y_{i}^{j},\left(\mu_{i}-y_{i}^{j}\right) R(\eta)\right)
$$

in contradiction of the inequality (14). This completes the proof. 


\subsection{Proof of Lemma 6}

Proposition 7 There exists a unique symmetric equilibrium $\left(p^{*}, x^{*}, y^{*}\right)$.

Proof. Uniqueness. The Inada conditions imply that the optimal mechanism will provide positive consumption at both dates, so both assets are held in equilibrium. Both assets will be held between date 0 and date 1 only if the returns on the two assets are equal. If $p r>1$ then the return on the long asset is greater than the return on the short asset between dates 0 and 1 and no one will hold the latter ; if $p r<1$ then the return on the short asset is greater than the return on the long asset between dates 0 and 1 and no one will hold the long asset. Then equilibrium requires that $p=1 / r$ at date 1 (Allen and Gale (1994)).

At the price $p=1 / r$, the short asset is dominated between dates 1 and 2 so no one will hold it. It follows that all consumption at date 1 is provided by the short asset and all consumption at date 2 is provided by the long asset. Then the market-clearing conditions are

$$
\begin{aligned}
& \sum_{k=1}^{K} \lambda_{k} \sigma_{k} x_{1}\left(\sigma_{k}\right)=n y, \\
& \sum_{k=1}^{K} \lambda_{k}\left(1-\sigma_{k}\right) x_{2}\left(\sigma_{k}\right)=n r(1-y) .
\end{aligned}
$$

At the price $p=1 / r$, intermediaries are indifferent between the two assets at date 0 . Thus, the quantities of the assets held in equilibrium are determined by the market-clearing conditions.

Finally, note that at the price $p=1 / r$, the right hand side of the budget constraint in (12) is equal to 1 for all $k$, so the choice of $x$ is independent of $y$. Strict concavity implies that there is at most one solution to the maximization problem. Hence, the equilibrium values are uniquely determined.

Existence. The existence of a symmetric equilibrium follows directly from the existence of a solution of the intermediary's decision problem (12). A solution exists because the choice set is compact and the objective function is continuous. The objective function is increasing, so the budget constraint holds as an equation for each $k$. Summing the budget constraint over $k$ we get

$$
\sum_{k} \lambda_{k}\left\{\sigma_{k} x_{1}\left(\sigma_{k}\right)+\left(1-\sigma_{k}\right) p x_{2}\left(\sigma_{k}\right)\right\}=n,
$$

where $p=1 / r$. Clearly, there exists a value of $0 \leq y \leq 1$ such that the market-clearing conditions (15) are satisfied. Then $(p, x, y)$ constitutes a symmetric equilibrium.

To study the effect of regulation of intermediaries, we take as given the choice of portfolio $y$ at date 0 and consider the determination of the consumption mechanism $x$ and the marketclearing price $p$. Call $(p, x, y)$ a regulated equilibrium if $x$ solves the problem (12) for the given values of $p$ and $y$, and $(x, y)$ satisfies the market-clearing conditions (15).

Proposition 8 For any $p$ sufficiently close to $p^{*}$, there exists a unique regulated equilibrium $(p, x, y)$.

Proof. Uniqueness. At any price $p$ close to $p^{*}$, the short asset is dominated between dates 1 and 2 so no one will hold it. It follows that all consumption at date 1 is provided by the short 
asset and all consumption at date 2 is provided by the long asset. Then the market-clearing conditions are

$$
\begin{aligned}
& \sum_{k=1}^{K} \lambda_{k} \sigma_{k} x_{1}\left(\sigma_{k}\right)=n y, \\
& \sum_{k=1}^{K} \lambda_{k}\left(1-\sigma_{k}\right) x_{2}\left(\sigma_{k}\right)=n r(1-y) .
\end{aligned}
$$

The budget constraints are

$$
\sigma_{k} x_{1}\left(\sigma_{k}\right)+\left(1-\sigma_{k}\right) p x_{2}\left(\sigma_{k}\right)=y+\operatorname{pr}(1-y),
$$

for each $k$. For the given $(p, y)$, strict concavity implies that there is at most one solution to the maximization problem. Hence, the equilibrium values are uniquely determined. If there exist two, distinct, regulated equilibria $(p, x, y)$ and $\left(p, x^{\prime}, y^{\prime}\right)$, say, then from the budget constraints and the fact that consumption at each date is a normal good, consumption must be uniformly higher at each date in one regulated equilibrium. But this is clearly impossible from the market-clearing conditions. Hence, there is at most one regulated equilibrium

Existence. Similar to the proof of Proposition 7.

\subsubsection{Proof of the lemma}

Let $X\left(\sigma_{k}, p, y\right)=\left(X_{1}\left(\sigma_{k}, p, y\right), X_{2}\left(\sigma_{k}, p, y\right)\right)$ denote the optimal mechanism for each value of $(p, y)$. An optimal mechanism is one that solves the problem:

$$
\begin{array}{ll}
\max & \sigma_{k} U\left(x_{1}\left(\sigma_{k}\right)\right)+\left(1-\sigma_{k}\right) U\left(x_{2}\left(\sigma_{k}\right)\right) \\
\text { s.t. } & \sigma_{k} x_{1}\left(\sigma_{k}\right)+\left(1-\sigma_{k}\right) x_{2}\left(\sigma_{k}\right) / r \leq y+p r(1-y)
\end{array}
$$

for each $k$. The necessary and sufficient conditions for this are

$$
U^{\prime}\left(X_{1}\left(\sigma_{k} ; p, y\right)\right)=r U^{\prime}\left(X_{2}\left(\sigma_{k} ; p, y\right)\right)
$$

and

$$
\sigma_{k} X_{1}\left(\sigma_{k} ; p, y\right)+\left(1-\sigma_{k}\right) p X_{2}\left(\sigma_{k} ; p, y\right)=y+p r(1-y)
$$

for every $k$.

The function $X\left(\sigma_{k}, p, y\right)$ is well defined and continuously differentiable for every $(p, y)$ in a sufficiently small neighborhood of $\left(p^{*}, y^{*}\right)$. This follows from the implicit function theorem and the regularity of the system (16)-(17) at $\left(p^{*}, y^{*}\right)$ :

$$
\operatorname{det}\left[\begin{array}{ll}
U^{\prime \prime}\left(X_{1}\left(\sigma_{k} ; p^{*}, y^{*}\right)\right) & -r U^{\prime \prime}\left(X_{2}\left(\sigma_{k} ; p^{*}, y^{*}\right)\right) \\
\sigma_{k} & \left(1-\sigma_{k}\right) p^{*}
\end{array}\right] \neq 0 .
$$

The market-clearing condition can be written as

$$
\sum_{k=1}^{K} \lambda_{k} \sigma_{k} X_{1}\left(\sigma_{k} ; p, y\right)=y
$$


since the other market-clearing condition is automatically satisfied by Walras' law. To show the existence of a regulated equilibrium for each $p$ sufficiently close to $p^{*}$ we can use the implicit function theorem again, noting that

$$
\begin{aligned}
\frac{\partial}{\partial y}\left(\sum_{k=1}^{K} \lambda_{k} \sigma_{k} X_{1}\left(\sigma_{k} ; p, y\right)-y\right) & =\sum_{k=1}^{K} \lambda_{k} \sigma_{k} \frac{\partial X_{1}\left(\sigma_{k} ; p^{*}, y^{*}\right)}{\partial y}-1 \\
& =-1,
\end{aligned}
$$

because $y+p^{*} r(1-y)=1$ is independent of $y$.

We next calculate the change in expected utility caused by a small change in $p$ at $p^{*}$.

$$
\begin{aligned}
& \frac{d}{d p} \sum_{k} \lambda_{k}\left\{\sigma_{k} U\left(X_{1}\left(\sigma_{k} ; p, y\right)\right)+\left(1-\sigma_{k}\right) U\left(X_{2}\left(\sigma_{k} ; p, y\right)\right)\right\} \\
= & \sum_{k} \lambda_{k}\left\{\sigma_{k} U^{\prime}\left(X_{1}\left(\sigma_{k} ; p, y\right)\right) \frac{\partial X_{1}}{\partial p}\left(\sigma_{k} ; p, y\right)+\left(1-\sigma_{k}\right) U^{\prime}\left(X_{2}\left(\sigma_{k} ; p, y\right)\right) \frac{\partial X_{2}}{\partial p}\left(\sigma_{k} ; p, y\right)\right\} \\
= & \sum_{k} \lambda_{k} U^{\prime}\left(X_{2}\left(\sigma_{k} ; p, y\right)\right)\left\{r \sigma_{k} \frac{\partial X_{1}}{\partial p}\left(\sigma_{k} ; p, y\right)+\left(1-\sigma_{k}\right) \frac{\partial X_{2}}{\partial p}\left(\sigma_{k} ; p, y\right)\right\} \\
= & \sum_{k} \lambda_{k} U^{\prime}\left(X_{2}\left(\sigma_{k} ; p, y\right)\right)\left\{r(1-y)-\left(1-\sigma_{k}\right) X_{2}\left(\sigma_{k} ; p, y\right)\right\} .
\end{aligned}
$$

Now suppose that the degree of relative risk aversion is less than one (the other case can be dealt with in exactly the same way). Then (16) implies that

$$
r x_{1}\left(\sigma_{k}\right)<r x_{2}\left(\sigma_{k}\right), \forall \sigma_{k}
$$

This in turn implies that $x_{1}\left(\sigma_{k}\right)$ and $\left(1-\sigma_{k}\right) x_{2}\left(\sigma_{k}\right)$ move in opposite directions. To see this, note that, within a fixed equilibrium, an increase in $\left(1-\sigma_{k}\right)$ must lead to a decrease in consumption at both dates (this follows directly from the fact that $x_{1}\left(\sigma_{k}\right)<x_{2}\left(\sigma_{k}\right) / r$ ). Then $\sigma_{k} x_{1}\left(\sigma_{k}\right)$ falls as $\left(1-\sigma_{k}\right)$ increases and so in order to satisfy the budget constraint it must be the case that $\left(1-\sigma_{k}\right) x_{2}\left(\sigma_{k}\right) / r$ increases. Assuming the distributions are not degenerate, it must be the case that

$$
\begin{aligned}
& \sum_{k} \lambda_{k} U^{\prime}\left(X_{2}\left(\sigma_{k} ; p, y\right)\right)\left\{r(1-y)-\left(1-\sigma_{k}\right) X_{2}\left(\sigma_{k} ; p, y\right)\right\} \\
> & \sum_{k} \lambda_{k} U^{\prime}\left(X_{2}\left(\sigma_{k} ; p, y\right)\right) \sum_{k} \lambda_{k}\left\{r(1-y)-\left(1-\sigma_{k}\right) X_{2}\left(\sigma_{k} ; p, y\right)\right\} \\
= & 0,
\end{aligned}
$$

where the last equation follows from the market-clearing condition

$$
\sum_{k} \lambda_{k}\left(1-\sigma_{k}\right) X_{2}\left(\sigma_{k} ; p, y\right)=r(1-y)
$$


Table 1

Examples

\begin{tabular}{||c|c|c|c|c|c|c|c||}
\hline \hline Example & $r$ & $y$ & $\left(q(1), p_{2}(1)\right)$ & $\left(q(2), p_{2}(2)\right)$ & $\left(c_{1}(1), c_{2}(1)\right)$ & $\left(c_{1}(2), c_{2}(2)\right)$ & $E[U]$ \\
\hline $1 \mathrm{~A}$ & 1.5 & 0.5 & $(0.5,0.67)$ & $(0.5,0.5)$ & $(1,1.5)$ & $(1,2)$ & 0.275 \\
$1 \mathrm{~B}$ & 0.5 & 0.64 & $(0.61,1)$ & $(0.39,0.89)$ & $(0.82,0.82)$ & $(1.28,1.44)$ & 0.054 \\
$1 \mathrm{C}$ & 0.3 & 0.79 & $(0.59,1)$ & $(0.41,1)$ & $(0.85,0.85)$ & $(1.21,1.21)$ & 0.016 \\
$2 A:$ & 0.5 & 0.5 & $(0.5,0.8)$ & $(0.5,0.8)$ & $(1,1.25)$ & $(1,1.25)$ & 0.112 \\
$2 N:$ & & 1.0 & & & $(0,0.25)$ & $(0,4.75)$ & 1.250 \\
3 & 1.6 & 0.5 & $(0.4,0.94)$ & $(0.6,0.42)$ & $(1.25,1.33)$ & $(0.83,2)$ & 0.213 \\
$4 \mathrm{~A}$ & 1.5 & 0.5 & $(0.33-0.75$, & $(0.25-0.67$, & $(1,1.5)$ & $(1,2)$ & 0.275 \\
& & & $0.25-1)$ & $0.38-1)$ & & & \\
$4 \mathrm{~B}$ & 0.95 & 0.49 & $(0.55-0.77$, & $(0.45-0.33$, & $(0.97,0.97)$ & $(0.97,2.05)$ & 0.157 \\
& & & $0.70-0.98)$ & $0.53-0.73)$ & & & \\
4C $S:$ & 0.5 & 0.67 & $(0.65,0.90)$ & $(0.35,1)$ & $(0.95,0.95)$ & $(0.95,1.41)$ & 0.045 \\
4C $B:$ & & 0 & & & $(0.77,0.77)$ & $(1.41,1.41)$ & 0.045 \\
\hline \hline
\end{tabular}




\section{References}

Aghion, P., P. Bacchetta and A. Banerjee (2000). "Currency Crises and Monetary Policy in an Economy with Credit Constraints," working paper, University College, London.

Allen, F. and D. Gale (1994). "Liquidity Preference, Market Participation and Asset Price Volatility," American Economic Review 84, 933-955.

— and - (1998). "Optimal Financial Crises," Journal of Finance 53, 1245-1284.

— and — (1999). Comparing Financial Systems. Cambridge: MIT Press.

— and - (2000a). "Financial Contagion," Journal of Political Economy 108, 1-33.

— and - (2000b). "Optimal Currency Crises" Carnegie-Rochester Conference Series on Public Policy 53, 177-230.

— and - (2000c). "Banking and Markets Addendum: Prudential Regulation of Banks," www.econ.nyu.edu/user/galed/papers.

Alonso, I. (1996). "On Avoiding Bank Runs," Journal of Monetary Economics 37, 73-87.

Bernanke. B. and M. Gertler (1989). "Agency Costs, Net Worth, and Business Fluctuations," American Economic Review 79, 14-31.

Bhattacharya, S. and D. Gale (1987). "Preference Shocks, Liquidity and Central Bank Policy," in W. Barnett and K. Singleton, eds., New Approaches to Monetary Economics. New York: Cambridge University Press.

Bhattacharya, S. and A. Thakor (1993) "Contemporary Banking Theory," Journal of Financial Intermediation 3, 2-50.

Bisin, A. and P. Gottardi (2000). "Decentralizing Incentive-Compatible Allocations in Adverse Selection Economies," working paper, New York University.

Bryant, J. (1980). "A Model of Reserves, Bank Runs, and Deposit Insurance," Journal of Banking and Finance 4, 335-344.

Calvo, G. (1988). "Servicing the Public Debt: The Role of Expectations," American Economic Review 78, 1411-1428.

Champ, B., B. Smith, and S. Williamson (1996). "Currency Elasticity and Banking Panics: Theory and Evidence," Canadian Journal of Economics 29, 828-864.

Chang, R. and A. Velasco (2000). "Financial Fragility and the Exchange Rate Regime," Journal of Economic Theory 92, 1-34. 
— and - (2001). "A Model of Financial Crises in Emerging Markets," Quarterly Journal of Economics 116, 489-517.

Chari, V. (1989). "Banking Without Deposit Insurance or Bank Panics: Lessons From a Model of the U.S. National Banking System," Federal Reserve Bank of Minneapolis Quarterly Review 13 (Summer), 3-19.

— and R. Jagannathan (1988). "Banking Panics, Information, and Rational Expectations Equilibrium," Journal of Finance 43, 749-60.

— and P. Kehoe (2000). "Financial Crises as Herds," working paper, Federal Reserve Bank of Minneapolis.

Cole, H. and T. Kehoe (2000). "Self-Fulfilling Debt Crises," Review of Economic Studies, 67, 91-116.

Cone, K. (1983). Regulation of Depository Institutions. Stanford University Ph.D. dissertation.

Corsetti, G., P. Pesenti and N. Roubini (1999). "Paper Tigers? A Model of the Asian Crisis," European Economic Review 43, 1211-1236.

Diamond, D. (1997). "Liquidity, Banks and Markets," Journal of Political Economy 105, 928-956.

— and P. Dybvig (1983). "Bank Runs, Liquidity, and Deposit Insurance," Journal of Political Economy 91, 401-419.

— and R. Rajan (2001). "Liquidity Risk, Liquidity Creation and Financial Fragility: A Theory of Banking," Journal of Political Economy 109, 287-327.

Flood, R. and N. Marion (1999). "Perspectives on Recent Currency Crises Literature," International Journal of Finance and Economics 4, 1-26.

Geanakoplos, J. and H. Polemarchakis (1986). "Existence, Regularity, and Constrained Suboptimality of Competitive Allocations When the Asset Market Is Incomplete," in Walter, Heller, Ross Starr, and David Starrett eds. Essays in honor of Kenneth J. Arrow: Volume 3, Uncertainty, information, and communication. Cambridge, New York and Sydney: Cambridge University Press, 65-95. Also reprinted in Debreu, Gerard, ed. (1996). General equilibrium theory. Volume 2. Elgar Reference Collection. International Library of Critical Writings in Economics, no. 67. Cheltenham, U.K.: Elgar; distributed by Ashgate, Brookfield, Vt. 67-97.

Gromb, D. and D. Vayanos (2001). "Equilibrium and Welfare in Markets with Financially Constrained Abitrageurs," working paper, MIT Sloan School of Management. 
Grossman, S. and O. Hart (1983). "An Analysis of the Principal-Agent Problem," Econometrica $\mathbf{5 1}, 7-45$.

Hellwig, M. (1994). "Liquidity Provision, Banking, and the Allocation of Interest Rate Risk," European Economic Review 38, 1363-1389.

- (1998). "Banks, Markets, and the Allocation of Risks in an Economy," Journal of Institutional and Theoretical Economics 154, 328-345.

Jacklin, C. (1986). "Demand Deposits, Trading Restrictions, and Risk Sharing," in E. Prescott and N. Wallace, eds., Contractual Arrangements for Intertemporal Trade (University of Minnesota Press, Minneapolis, MN).

— and S. Bhattacharya (1988). "Distinguishing Panics and Information-Based Bank Runs: Welfare and Policy Implications," Journal of Political Economy 96, 568-592.

Krugman, P. (1979). "A Model of Balance-of-Payments Crises," Journal of Money Credit and Banking 11, 311-325.

Martin, A. (2000). "Liquidity Provision vs. Deposit Insurance: Preventing Bank Panics without Moral Hazard," working paper, Federal Reserve Bank of Minneapolis.

Matutes, C. and X. Vives (1996). "Competition for Deposits, Fragility, and Insurance," Journal of Financial Intermediation 5, 184-216.

— and - (2000). "Imperfect Competition, Risk Taking, and Regulation in Banking," European Economic Review 44, 1-34.

Morris, S. (2000). "Contagion," Review of Economic Studies 67, 57-78.

Morris, S. and H. S. Shin (1998). "Unique Equilibrium in a Model of Self-Fulfilling Currency Attacks," American Economic Review 88, 587-597.

Morris, S. and H. S. Shin (2000). "Global Games: Theory and Applications," working paper, Yale University.

Obstfeld, M. (1986). "Rational and Self-Fulfilling Balance of Payments Crises," American Economic Review 76, 72-81.

Peck, J. and K. Shell (1999). "Bank Portfolio Restrictions and Equilibrium Bank Runs," working paper, Cornell University.

Postlewaite, A. and X. Vives (1987). "Bank Runs as an Equilibrium Phenomenon," Journal of Political Economy 95, 485-491.

Prescott, E. and R. Townsend (1984a). "Pareto Optima and Competitive Equilibria with Adverse Selection and Moral Hazard, Econometrica 52, 21-45. 
Prescott, E. and R. Townsend (1984b). "General Competitive Analysis in an Economy with Private Information," International Economic Review 25, 1-20.

von Thadden, E.-L. (1999). "Liquidity Creation through Banks and Markets: Multiple Insurance and Limited Market Access," European Economic Review 43, 991-1006.

Wallace, N. (1988). "Another Attempt to Explain an Illiquid Banking System: The Diamond and Dybvig Model with Sequential Service Taken Seriously," Federal Reserve Bank of Minneapolis Quarterly Review 12 (Fall), 3-16.

Wallace, N., (1990). "A Banking Model in which Partial Suspension is Best," Federal Reserve Bank of Minneapolis Quarterly Review 14 (Fall), 11-23.

Zame, W. (1993). "Efficiency and the Role of Default when Security Markets are Incomplete," American Economic Review 83, 1142-1164. 